\title{
Effect of the graft ratio on the properties
}

\section{of polythiophene-g-poly(ethylene glycol)}

Silvana Maione, ${ }^{1,2}$ Georgina Fabregat, ${ }^{1,2}$ Luis J. del Valle, ${ }^{2}$ Anca-Dana Bendrea, ${ }^{3}$ Luminita Cianga, ${ }^{3}$ Ioan Cianga, ${ }^{3}$ Francesc Estrany, ${ }^{1}$ and Carlos Alemán ${ }^{2,3, *}$

${ }^{1}$ Departament d'Enginyeria Química, E. T. S. d'Enginyers Industrials, Universitat Politècnica de Catalunya, Diagonal 647, 08028 Barcelona, Spain.

${ }^{2}$ Center for Research in Nano-Engineering, Universitat Politècnica de Catalunya, Campus Sud, Edifici C', C/Pasqual i Vila s/n, Barcelona E-08028, Spain

3 "Petru Poni" Institute of Macromolecular Chemistry, 41A, Grigore-Ghica Voda Alley, 700487, Iasi, Romania

*Corresponding author: Carlos Alemán (carlos.aleman@upc.edu) 


\section{ABSTRACT}

Graft copolymers formed by anchoring poly(ethylene glycol) (PEG) chains to conjugated polythiophene have been prepared by copolymerizing two compounds: unsubstituted $\alpha$-terthiophene $\left(\mathrm{Th}_{3}\right)$ and a thiophene-derived macromonomer having an $\alpha$-terthiophene conjugated sequence and one $\mathrm{Th}_{3}$ bearing a PEG chain with molecular weight of 2000 as substitute at the 3-position of the central heterocycle $\left(\mathrm{Th}_{3}-\mathrm{PEG}_{2000}\right)$. The grafting ratio of the resulting copolymers $\left(\mathrm{PTh}_{3}{ }^{*}-g\right.$-PEG), which were obtained using 75:25 and 50:50 $\mathrm{Th}_{3}-\mathrm{PEG}_{2000}: \mathrm{Th}_{3}$ weight ratios, is significantly smaller than that of copolymers derived from polymerization of macromonomers consisting of a $\alpha$ pentathiophene sequence in which the central ring bears a PEG chain of $M_{w}=2000$ $\left(\mathrm{PTh}_{5^{-}} g-\mathrm{PEG}\right)$. The electroactivity and electrochemical stability of $\mathrm{PTh}_{3}{ }^{*}-\mathrm{g}-\mathrm{PEG}$ is not only higher than that of $\mathrm{PTh}_{5}-\mathrm{g}$-PEG but also higher than that of $\mathrm{PTh}_{3}$, the latter presenting a very compact structure that makes difficult the access and escape of dopant ions into the polymeric matrix during the redox processes. Furthermore, the optical $\pi-\pi^{*}$ lowest transition energy of $\mathrm{PTh}_{3}{ }^{*}-g$-PEG is lower than that of both $\mathrm{PTh}_{5}-g$-PEG and $\mathrm{PTh}_{3}$. These properties, combined with suitable wettability and roughness, result in an excellent behavior as bioactive platform of $\mathrm{PTh}_{3}{ }^{*}-\mathrm{g}$-PEG copolymers, which are more biocompatible, in terms of cellular adhesion and proliferation, and electro-compatible than $\mathrm{PTh}_{5}-g-\mathrm{PEG}$.

Keywords: Bioactive platforms; Bottle-brush polymers; Cell proliferation; Conjugated polymers; Grafted copolymers; Molecular brushes 


\section{INTRODUCTION}

Graft copolymers made of components with very different properties are receiving increasing attention. ${ }^{1-4}$ This kind of polymers are typically considered as hybrid materials able to amplify the properties of their individual components, exhibiting unusual characteristics because of their confined structure, compact organization and notable chain end effects.

Bottle-brush polymers, also called molecular brushes, are a special class of graft copolymers that usually contain a linear polymer backbone and densely grafted oligomeric side chains. ${ }^{5,6}$ The unique self-assembly in solution or melt state and their potential application as nano-, bio-, and photonic-materials have drawn considerable attention. ${ }^{7,8}$ Synthetically, such macromolecular architectures can be prepared by three major approaches: (i)-grafting onto, (ii)-grafting from and (iii)- grafting through, each approach having its intrinsic advantages and drawbacks. ${ }^{5}$ The concept of brush polymers has been employed in the synthesis of conjugated polymers to increase solubility, as well as to demonstrate unique optical properties and morphology control. $^{9,10}$

Among bottle-brush copolymers, those formed by semiconducting conjugated polythiophene (PTh) backbone and isolating polymers have been prepared in an attempt to combine different interesting properties in one material and to achieve multifunctional polymers. For example, the very limited solubility and processability of unsubstituted PTh has been improved by grafting polystyrene, ${ }^{11,12}$ poly(methyl acrylate $)^{13}$ or poly(ethylene glycol) ${ }^{14}$ (PEG) to the polyheterocyclic backbone. Grafting strategies have been also used to develop thermochromic polymers by anchoring thermoresponsive poly(N-isopropylacrylamide) and PEG on PTh backbone $e^{15,16}$ as well 
as donor- $\pi$-acceptor molecular species by preparing PTh-graft-(styrene-graft- $\left.\mathrm{C}_{60}\right)$ copolymers. $^{17}$

Most of the above-mentioned example of PTh bottle-brush copolymers were obtained by "grafting from" methods using chemical polymerization. Similar architectures were also reported by employing the same method but via electrochemical polymerization. ${ }^{18,19}$ The "grafting through" approach for synthesis of molecular brushes offer the advantage of well-defined grafting density and side chain length, defect-free polymer structure, and even easy access to block copolymer synthesis. ${ }^{10,11}$ Tacking in account these emphasized advantages, amphiphilic bottle-brush copolymers formed by anchoring PEG side chains to conjugated PTh backbone has been very recently prepared by using the "grafting through" approach via electrochemical or chemical polymerization. $^{20,21}$ Their suitability for various biotechnological and biomedical applications was demonstrated, as well. More specifically, thiophene-based oligomers consisting of a pentathiophene sequence in which the central ring bears a PEG side chain with molecular weight $\left(\mathrm{M}_{\mathrm{w}}\right)$ of 1000 or 2000 at the 3-position $\left(\mathrm{Th}_{5}-\mathrm{PEG}_{1000}\right.$ or $\mathrm{Th}_{5}-\mathrm{PEG}_{2000}$, respectively) were prepared by chemical synthesis and subsequently polymerized by potentiostatic methods, giving rise to $\mathrm{PTh}_{5^{-}} g-\mathrm{PEG}_{1000}$ or $\mathrm{PTh}_{5^{-}}$$\mathrm{PEG}_{2000}$, respectively (Scheme 1). ${ }^{20}$
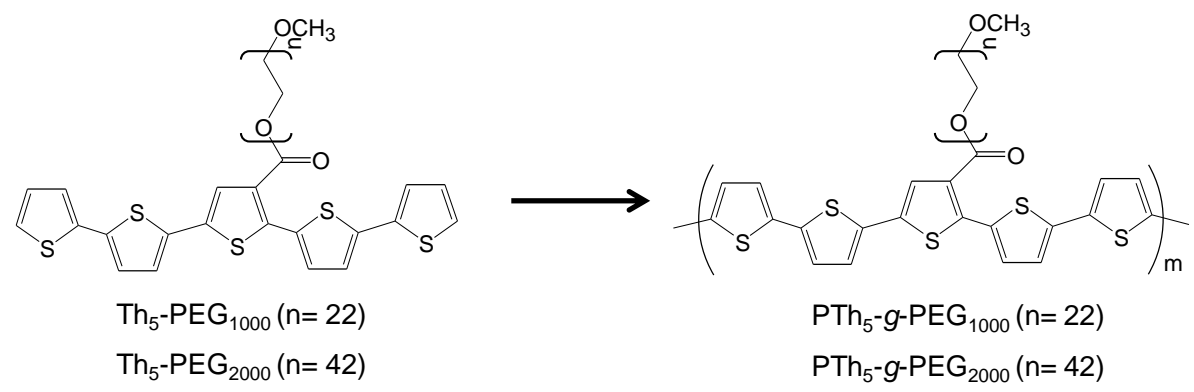

Scheme 1 
The influence of the polymerization potential, the length of the PEG branches and the dopant agent on the structure and properties of these graft copolymers was carefully examined. ${ }^{20}$ Results indicated that the two $\mathrm{PTh}_{5^{-}} g-\mathrm{PEG}_{\mathrm{n}}$ derivatives tend to undergo a high number of anodic oxidation processes, which give place to the formation of charged species. In order to take profit of the distribution of charged species on the surface, the performance of these materials as active surfaces for the selective adsorption of proteins was tested. As it was expected, the affinity of these materials, especially $\mathrm{PTh}_{5}-\mathrm{g}-\mathrm{PEG}_{2000}$, towards globular proteins is higher than towards fibrillar proteins. $^{20}$

More recently, the ability of the $\mathrm{PTh}_{5^{-}} g-\mathrm{PEG}_{\mathrm{n}}$ copolymers as cellular matrices was investigated, ${ }^{22}$ their behavior being significantly better than that reported for other biocompatible CPs, as for example poly(3,4-ethylenedioxythiophene). ${ }^{23}$ This result was fully consistent with the hydrophilicity observed for the graft copolymers, ${ }^{22}$ which increases with the molecular weight of the PEG chain, and with the biphasic molecular organization predicted by atomistic molecular dynamics simulations. ${ }^{22}$ The behavior as bioactive matrices for cell viability was also proved by copolymers obtained by Suzuki polycondensation. $^{21}$

In this work we take advantage of a new macromonomer to investigate the effect of the PEG / Th ratio in the properties of graft copolymers made of PEG attached to PTh $\left(\mathrm{PTh}_{n}-\mathrm{g}\right.$-PEG). More specifically, the synthesis and characterization of a macromonomer made of $\alpha$-terthiophene $\left(\mathrm{Th}_{3}\right)$ bearing a PEG chain of $\mathrm{M}_{\mathrm{W}}=2000$ at the 3-position of the central heterocycle $\left(\mathrm{Th}_{3}-\mathrm{PEG}_{2000}\right.$, Scheme 2$)$, was recently reported by some of us. ${ }^{24}$ Although our first aim was to increase the PEG / Th ratio of graft copolymers by preparing $\mathrm{PTh}_{3-}-\mathrm{g}-\mathrm{PEG}_{2000}$ (Scheme 2), anodic polymerization of $\mathrm{Th}_{3-}$ 
$\mathrm{PEG}_{2000}$ was completely unsuccessful even varying the experimental conditions (i.e. solvents, electrolyte, electrode, potential, etc) with respect to those used for $\mathrm{PTh}_{5^{-}} \mathrm{g}_{-}$ $\mathrm{PEG}_{2000}{ }^{20,21}$ This drawback was attributed to the steric effects provoked by the PEG chain at the reactive positions of the thiophene rings, which make difficult the polymerization process and preclude the formation of a homogeneous and stable film. In order to overcome this limitation, we have added $\mathrm{Th}_{3}$ to the polymerization medium (Scheme 3). The graft copolymer derived from the anodic copolymerization of $\mathrm{Th}_{3^{-}}$ $\mathrm{PEG}_{2000}$ and $\mathrm{Th}_{3}$, which has been denoted $\mathrm{PTh}_{3}{ }^{*}-g-\mathrm{PEG}_{2000}$, presents a PEG / Th ratio significantly lower than that of $\mathrm{PTh}_{5^{-}} g-\mathrm{PEG}_{2000}$.

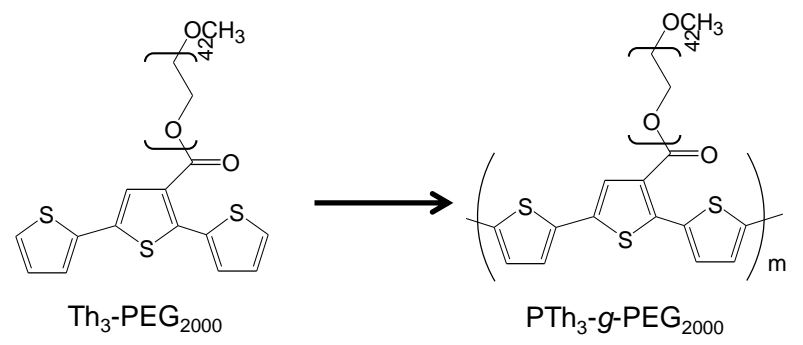

Scheme 2
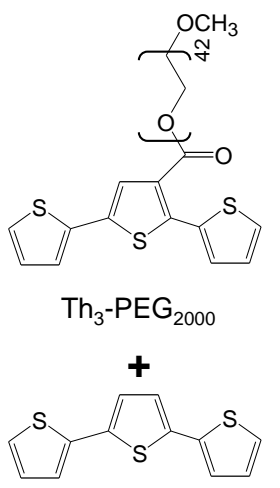

$\mathrm{Th}_{3}$

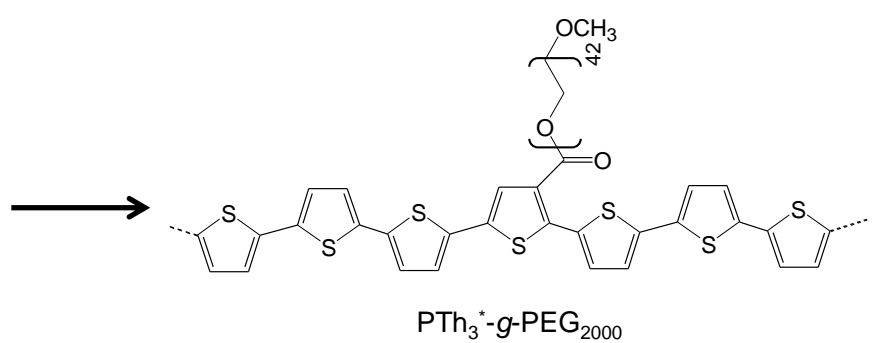

Scheme 3

In this work we evaluate the properties of $\mathrm{PTh}_{3}{ }^{*}-g-\mathrm{PEG}_{2000}$ comparing them not only with those obtained for $\mathrm{PTh}_{5}{ }^{-} g-\mathrm{PEG}_{2000}$ but also with those of poly( $\alpha$-terthiophene) $\left(\mathrm{PTh}_{3}\right)$. More specifically, surface (morphology, topography and wettability) and bulk 
properties (optical and electrochemical) of $\mathrm{PTh}_{3}{ }^{*}-g-\mathrm{PEG}_{2000}$ and $\mathrm{PTh}_{3}$ prepared under identical experimental conditions have been investigated. Furthermore, the cytotoxicity, biocompatibility and electrocompatibility of $\mathrm{PTh}_{3}{ }^{*}-g-\mathrm{PEG}_{2000}$ have been examined to analyze the potential advantages of this copolymer with respect to $\mathrm{PTh}_{5}-\mathrm{g}-\mathrm{PEG}_{2000}$ in biomedical applications.

\section{METHODS}

Materials. All used solvents were purified and dried by usual methods. PEG with $\mathrm{M}_{\mathrm{w}}=2000$ (Aldrich), ), 3-thiophene carboxylic acid (Aldrich), 2-thiophene boronic acid (Aldrich),N,N'-dicyclohexylcarbodiimide (DCCI) (Merk), 4-dimethylamino pyridine (DMAP) (Aldrich), Pd(PPh3)4 (Aldrich), anhydrous lithium perchlorate (SigmaAldrich) and $\mathrm{Th}_{3}$ (Aldrich) were used as received.

For cell culture experiments, Cos-7 cells were purchased from ATCC (USA). Dulbecco's phosphate buffered saline solution (PBS) without calcium chloride and magnesium chloride, Dulbecco's modified Eagle's medium (DMEM, with $4500 \mathrm{mg}$ of glucose/L, $110 \mathrm{mg}$ of sodium pyruvate/L and (2 mM) L-glutamine), penicillinstreptomycin, 3-(4,5-dimethylthiazol-2-yl)-2,5-diphenyltetrazolium bromide (MTT, 97.5\%) and trypsin-EDTA solution (0.05\% trypsin, 0.02\% EDTA) were all purchased from Sigma-Aldrich (USA). Fetal bovine serum (FBS) and trypan blue stain (0.4\%) were purchased from Gibco, UK. Dimethyl sulfoxide (99.0\%) was purchased from Panreac Quimica S.A.U. (Spain) and sodium azide $(\mathrm{NaN} 3, \geq 99.5 \%)$ from SigmaAldrich (USA).

For protein adsorption, collagen solution type I from calf skin $(0.1 \%$ solution in 0.1 M acetic acid) was purchased from Sigma-Aldrich. 
Synthesis and characterization of oligomer $T h_{3}-P E G_{2000}$. By using the synthetic strategy already reported, ${ }^{24} \mathrm{Th}_{3}-\mathrm{PEG}_{2000}$ was synthesized following the chemical route presented in Scheme 4. The ${ }^{1} \mathrm{H}-\mathrm{NMR}$ spectrum of $\mathrm{Th}_{3}-\mathrm{PEG}_{2000}$ in acetone- $\mathrm{d}_{6}$ was in excellent agreement with that already reported. ${ }^{24}$

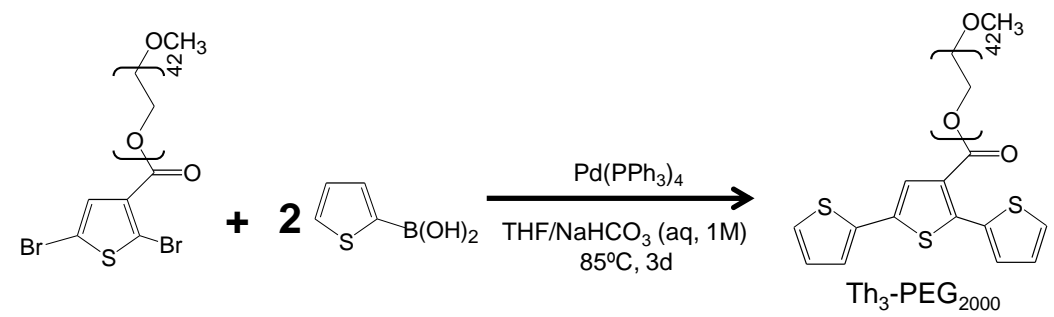

Scheme 4

Polymerization. All electrochemical assays, including polymerizations, were carried out in a standard three electrode cell of $50 \mathrm{~mL}$ under nitrogen atmosphere $(99.995 \%$ in purity) at room temperature. The anodic compartment was filled with $10 \mathrm{~mL}$ of a $1 \mathrm{mM}$ acetonitrile solution of a $\mathrm{Th}_{3}-\mathrm{PEG}_{2000}: \mathrm{Th}_{3}$ mixture containing $0.1 \mathrm{M} \mathrm{LiClO}_{4}$ as supporting electrolyte, while the cathodic compartment was filled with $10 \mathrm{~mL}$ of the same electrolyte solution. Steel AISI 316 sheets of $2 \mathrm{~cm}^{2}$ area (surface roughness determined by AFM: $11.4 \AA$ ) were employed as working and counter electrodes. The reference electrode was an $\mathrm{Ag} \mid \mathrm{AgCl}$ electrode containing a $\mathrm{KCl}$ saturated aqueous solution $\left(\mathrm{E}^{0}=0.222 \mathrm{~V}\right.$ at $\left.25^{\circ} \mathrm{C}\right)$, which was connected to the working compartment through a salt bridge containing the electrolyte solution.

$\mathrm{PTh}_{3}{ }^{*}-g-\mathrm{PEG}_{2000}$ films were prepared by chronoamperometry (CA) using a constant potential of $1.0 \mathrm{~V}$ and considering two $\mathrm{Th}_{3}-\mathrm{PEG}_{2000}: \mathrm{Th}_{3}$ weight ratios $(75: 25$ and 50:50). After trials using different polymerization times ( $\theta=300,400$ and $500 \mathrm{~s})$, all $\mathrm{PTh}_{3}{ }^{*}-g-\mathrm{PEG}_{2000}$ films for analyses were prepared using $\theta=400 \mathrm{~s} . \mathrm{PTh}_{3}$ films were 
prepared using the same experimental conditions but considering a $1 \mathrm{mM} \mathrm{Th}_{3}$ acetonitrile solution with $0.1 \mathrm{M} \mathrm{LiClO}_{4}$ as the generation medium.

Contact profilometry. The thickness of the films was determined using a Dektak 150 stylus profilometer (Veeco, Plainview, NY). Different scratches were intentionally provoked on the films and measured to allow statistical analysis of data. Imaging of the films was conducted using the following optimized settings: tip radius $=2.5 \mu \mathrm{m}$; stylus force $=1.5 \mathrm{mg}$; scan length $=1 \mu \mathrm{m}$; and speed $=1.5 \mathrm{~nm} / \mathrm{s}$. The thickness was measured using two different items: (i) the vertical distance (VD), which corresponds to the difference between the height polymer and the height of the steel substrate without any average; and (ii) the average step height (ASH), which measures the difference between the average height of the polymer and the average height of the steel substrate.

X-Ray photoelectron spectroscopy (XPS). XPS analyses were performed in a SPECS system equipped with a high-intensity twin-anode X-ray source XR50 of Mg/Al (1253 $\mathrm{eV} / 1487 \mathrm{eV}$ ) operating at $150 \mathrm{~W}$, placed perpendicular to the analyzer axis, and using a Phoibos 150 MCD-9 XP detector. The X-ray spot size was $650 \mu \mathrm{m}$. The pass energy was set to 25 and $0.1 \mathrm{eV}$ for the survey and the narrow scans, respectively. Charge compensation was achieved with a combination of electron and argon ion flood guns. The energy and emission current of the electrons were $4 \mathrm{eV}$ and $0.35 \mathrm{~mA}$, respectively. For the argon gun, the energy and the emission current were $0 \mathrm{eV}$ and $0.1 \mathrm{~mA}$, respectively. The spectra were recorded with a pass energy of $25 \mathrm{eV}$ in $0.1 \mathrm{eV}$ steps at a pressure below $6 \times 10^{-9}$ mbar. These standard conditions of charge compensation resulted in a negative but perfectly uniform static charge. The $\mathrm{C} 1 \mathrm{~s}$ peak was used as an internal reference with a binding energy of $284.8 \mathrm{eV}$. The surface composition was determined using the manufacturer's sensitivity factors. 
FTIR spectroscopy. FTIR spectra were recorded on a Nicolet 6700 spectrophotometer. For this purpose, films were scrapped off from the electrode and dried under vacuum. FTIR spectra were recorded using $\mathrm{KBr}$ discs at a $6 \mathrm{~cm}^{-1}$ resolution (60 scans).

Scanning electron microscopy (SEM). SEM studies were performed to investigate the effect of the applied synthetic approach on the surface morphology of the films. Dried samples were placed in a Focused Ion Beam Zeiss Neon 40 scanning electron microscope operating at $5 \mathrm{kV}$, equipped with an EDX spectroscopy system.

Atomic force microscopy (AFM). Topographic images were obtained with an AFM Dimension 3100 microscope and an AFM Multimode TM microscope using a NanoScope IV controller (Bruker) under ambient conditions in tapping mode. The root mean square roughness $(\mathrm{Rq})$, which is the average height deviation taken from the mean data plane, was determined using the statistical application of the NanoScope Analysis software (1.20, Veeco). AFM measurements were performed on various parts of the films, which produced reproducible images similar to those displayed in this work. The scan window size was $5 \times 5 \mu \mathrm{m}^{2}$.

Wettability. Contact angle measurements were obtained using the sessile water drop method at room temperature and controlled humidity. Images of $5 \mu \mathrm{L}$ distillated water drops on the nanomembrane surfaces were recorded after stabilization (10 s) with the equipment OCA 20 (DataPhysics Instruments GmbH, Filderstadt). The software SCA20 was used to analyze the images and acquire the contact angle value. Contact angle values were obtained as the average of 10 independent measures for each sample.

$U V$-vis spectroscopy. Spectra of $\mathrm{PTh}_{3}{ }^{*}-g-\mathrm{PEG}_{2000}$ and $\mathrm{PTh}_{3}$ films were obtained using a UV-vis-NIR Shimadzu 3600 spectrophotometer equipped with a tungsten 
halogen visible source, a deuterium arc UV source, a photomultiplier tube UV-vis detector, and an InGaAs photodiode and cooled $\mathrm{PbS}$ photocell NIR detectors. Spectra were recorded in the absorbance mode using the integrating sphere accessory (model ISR-3100), the wavelength range being 185-3300 $\mathrm{nm}$. The interior of the integrating sphere was coated with highly diffuse $\mathrm{BaSO}_{4}$ reflectance standard. Uncoated ITO glass was used as reference. Films were deposited on ITO-glass electrodes for measurements. Single-scan spectra were recorded at a scan speed of $60 \mathrm{~nm} / \mathrm{min}$. Measurements, data collection and data evaluation were controlled by the computer software UVProbe version 2.31 .

Electrochemical properties. The electroactivity and electrostability were studied by cyclic voltammetry $(\mathrm{CV})$ using a $0.1 \mathrm{M}$ phosphate buffer saline solution $(\mathrm{PBS} ; \mathrm{pH}=7.4$ adjusted with $\mathrm{NaOH}$ ). The initial and final potentials were $-0.40 \mathrm{~V}$, and the reversal potential was $0.80 \mathrm{~V}$. A scan rate of $50 \mathrm{mV} / \mathrm{s}$ was used in all cases. The electroactivity and electrostability were determined through direct measure of the anodic and cathodic areas in the control voltammograms using the GPES software.

Cytotoxicity, cellular adhesion and cellular proliferation. All cellular assays were performed using Cos-7 cells, which are fibroblast-like, from monkey kidney. These carcinogenic cells were selected due to their fast growth. Cells were cultured in DMEM high glucose supplemented with 10\% FBS, penicillin (100 units/mL), and streptomycin (100 $\mu \mathrm{g} / \mathrm{mL})$. The cultures were maintained in a humidified incubator with an atmosphere of $5 \% \mathrm{CO}_{2}$ and $95 \% \mathrm{O}_{2}$ at $37^{\circ} \mathrm{C}$. Culture media were changed every two days. When the cells reached $80-90 \%$ confluence, they were detached using $1-2 \mathrm{~mL}$ of $\operatorname{trypsin}\left(0.25 \%\right.$ trypsin/EDTA) for $5 \mathrm{~min}$ at $37{ }^{\circ} \mathrm{C}$. Finally, cells were re-suspended in 5 
$\mathrm{mL}$ of fresh medium and their concentration was determined by counting with a Neubauer camera using $0.4 \%$ trypan blue as a vital dye.

$\mathrm{PTh}_{3}{ }^{*}{ }^{-}-\mathrm{PEG}_{2000}\left(75: 25\right.$ and 50:50 $\left.\mathrm{Th}_{3}-\mathrm{PEG}_{2000}: \mathrm{Th}_{3}\right)$ and $\mathrm{PTh}_{3}$ deposited onto steel AISI 316 sheets of $1 \mathrm{~cm}^{2}$ were placed in plates of 24 wells and sterilized using UV irradiation for $15 \mathrm{~min}$ in a laminar flux cabinet. Controls for cytotoxicity were simultaneously performed by culturing cells on the surface of the tissue culture polystyrene (TCP) plates and steel plates, whereas steel plates were the only control for adhesion and proliferation assays. For cytotoxicity and adhesion assays, an aliquot of 50 $\mu \mathrm{L}$ containing $5 \times 10^{4}$ cells was deposited on the film of each well. Then, attachment of cells to the film surface was promoted by incubating under culture conditions for 30 min. Finally, $500 \mu \mathrm{L}$ of the culture medium were added to each well. After $24 \mathrm{~h}$, all cells in the well were quantified to evaluate the cytotoxicity of the materials, whereas cellular adhesion was determined by quantifying exclusively the cells attached to $\mathrm{PTh}_{3}{ }^{*}$ $g-\mathrm{PEG}_{2000}, \mathrm{PTh}_{3}$ or the control. For proliferation assays, the $50 \mu \mathrm{L}$ aliquots deposited on each well contained $2 \times 10^{4}$ cells. Quantification of viable cells onto the evaluated materials was performed after 72 hours of culture.

Cell adhesion and viability were evaluated by the colorimetric MTT [3-(4,5dimethylthiazol-2-yl)-2,5-diphenyltetrazolium bromide] assay, which determines the cell viability. ${ }^{25}$ This assay measures the ability of the mitochondrial dehydrogenase enzyme of viable cells to cleave the tetrazolium rings of the MTT and form formazan crystals, which are impermeable to cell membranes and, therefore, are accumulated in healthy cells. This process is detected by a color change: the characteristic pale yellow of MTT transforms into the dark-blue of formazan crystals. Specifically, $50 \mathrm{~mL}$ of MTT solution $(5 \mathrm{mg} / \mathrm{mL}$ in PBS) were added to each well. After $3 \mathrm{~h}$ of incubation, samples 
were washed twice with PBS and stored in clean wells. In order to dissolve formazan crystals, $1 \mathrm{~mL}$ of DMSO/methanol/water (70/20/10 \% v/v) was added. Finally, the absorbance at $540 \mathrm{~mm}$ was measured using a UV-vis spectrophotometer (UV-3600, Shimadzu). The resulting viability results were normalized to TCP control as relative percentages. Results were derived from the average of four replicates $(n=4)$ for each independent experiment.

The toxicity of the $\mathrm{Th}_{3}$ monomer was determined using Cos-7 cells. From a stock $100 \times 10^{-3} \mathrm{M}$ monomer solution in acetonitrile concentrations ranging from $0.2 \times 10^{-3}$ to $20 \times 10^{-3} \mathrm{M}$ in culture medium were prepared by dilution. Experiments were carried out at 96 wells plates. An aliquot of $50 \mathrm{~mL}$ of $2 \times 10^{5}$ cells $/ \mathrm{mL}$ was seeded at each well and $50 \mathrm{~mL}$ of monomer solution was added to reach a final volume of $100 \mathrm{~mL}$ in each well with monomer concentrations ranging from 0.1 to $10 \times 10^{-3} \mathrm{M}$. Controls were run at the same plate without monomer (zero concentration) and with acetonitrile as solvent control. The cells were maintained in culture for $24 \mathrm{~h}$. After this, the MMT assay was used to determine the cell viability.

Adsorption of collagen. We have used a $0.1 \%(1 \mathrm{mg} / \mathrm{mL})$ solution of calf skin collagen in $0.1 \mathrm{M}$ acetic acid (Sigma-Aldrich). A thin protein layer coating was deposited onto the surface of $\mathrm{PTh}_{3}{ }^{*}-g-\mathrm{PEG}_{2000}$ and $\mathrm{PTh}_{3}$ films to facilitate the attachment of anchorage-dependent cells. For this purpose, films were placed into a culture plate of 24 wells, and sterilized by exposure to UV light during $15 \mathrm{~min}$. The collagen solution $(1 \mathrm{mg} / \mathrm{mL})$ was diluted 10 -fold with sterile water to obtain a working concentration of $0.01 \%$. Then, films were superficially coated with $10 \mu \mathrm{g} / \mathrm{cm}^{2}$. In order to facilitate the binding of the collagen to the films, materials were incubated overnight at $37^{\circ} \mathrm{C}$. The excess of fluid was removed from the coated surface, and allows it to dry 
overnight at room temperature in the laminar flux cabinet. Finally, the coated films were rinsed with PBS before seeding cells onto the matrix for evaluated the cytotoxicity and cellular adhesion.

Statistical analyses. Statistical analysis were performed with a confidence level of 95\% ( $\mathrm{p}<0.05)$ using one-way ANOVA followed by Tukey's test.

\section{RESULTS AND DISCUSSION}

\section{Preparation of $\mathrm{PTh}_{3}{ }^{*}-g-\mathrm{PEG}_{2000}$}

Independently of the polymerization time, as prepared $\mathrm{PTh}_{3}{ }^{*}-g-\mathrm{PEG}_{2000}$ and $\mathrm{PTh}_{3}$ films doped with $\mathrm{ClO}_{4}^{-}$showed brownish orange and dark blue color, respectively, which represent a significant difference with respect to the intense yellow color of $\mathrm{PTh}_{5-} g-\mathrm{PEG}_{2000}$ prepared with the same dopant. ${ }^{22}$ All these materials were completely insoluble, as is usual in polymers prepared by anodic polymerization.

The thickness of $\mathrm{PTh}_{3}{ }^{*}-g-\mathrm{PEG}_{2000}$ and $\mathrm{PTh}_{3}$ films was determined by profilometry, results considering the VD and $\mathrm{ASH}$ procedures being fully consistent (ESI). The thickness of all films was around $0.9 \pm 0.1 \mu \mathrm{m}$, independently of the content of $\mathrm{Th}_{3^{-}}$ $\mathrm{PEG}_{2000}$ units. This value is noticeably higher than that reached for $\mathrm{PTh}_{5}-g-\mathrm{PEG}_{2000}$ using a polymerization time of $1500 \mathrm{~s}$ and a potential of $0.75 \mathrm{~V}$ (i.e. $109 \pm 5 \mathrm{~nm}$ ), ${ }^{23}$ which is fully consistent with the poor polymerizability of $\mathrm{Th}_{3}-\mathrm{PEG}_{2000}$ macromonomers. On the other hand, as the final composition of the two copolymers has been only determined qualitatively due to their insolubility (see below), the terminology used in this work always refer to the feeding composition (i.e. 75:25 and 50:50 $\mathrm{Th}_{3^{-}}$ $\left.\mathrm{PEG}_{2000}: \mathrm{Th}_{3}\right)$. 
Table 1 compares the atomic percent compositions obtained for $\mathrm{PTh}_{3}{ }^{*}-g-\mathrm{PEG}_{2000}$ and $\mathrm{PTh}_{3}$ using XPS (ESI). The C/S ratio obtained for $\mathrm{PTh}_{3}(3.9)$ is in good agreement with the expected value (4.0). However, the $\mathrm{C} / \mathrm{S}$ ratio of the two $\mathrm{PTh}_{3}{ }^{*}-g-\mathrm{PEG}_{2000}$ copolymers (5.0 and 4.5 for $75: 25$ and 50:50, respectively) is considerably closer to that expected for $\mathrm{PTh}_{3}$ than to that of $\mathrm{PTh}_{3}-g-\mathrm{PEG}_{2000}$ (32.7), corroborating the difficulties associated to the polymerization of $\mathrm{Th}_{3}-\mathrm{PEG}_{2000}$ macromonomers. These values confirm that the content of $\mathrm{Th}_{3}$ units is higher for the 50:50 copolymer than for the 75:25 one. On the other hand, the $\mathrm{Cl} / \mathrm{S}$ ratio of $\mathrm{PTh}_{3}-\mathrm{g}-\mathrm{PEG}_{2000}(0.30$ and 0.15 for $75: 25$ and $50: 50$, respectively) and $\mathrm{PTh}_{3}(0.23)$ reflect that the doping level is relatively low in all cases, especially for the systems with a higher content of $\mathrm{Th}_{3}$ units.

The FTIR spectra of $\mathrm{PTh}_{3}{ }^{*}-g-\mathrm{PEG}_{2000}$ and $\mathrm{PTh}_{3}$ are displayed in Figure 1. The $\mathrm{C}_{\alpha}-\mathrm{H}$ out of plane ring deformation absorption in the spectrum of $\mathrm{PTh}_{3}$ is detected at $735 \mathrm{~cm}^{-1}$ as a shoulder only, proving that the polymerization of $\mathrm{Th}_{3}$ mainly involves linkages at the $\alpha-\alpha$ positions (i.e. $\mathrm{PTh}_{3}$ chains tend to grow linearly). This is consistent with the absorption shoulder detected at $3070 \mathrm{~cm}^{-1}$ for $\mathrm{PTh}_{3}$, which also evidences a low fraction of hydrogen atoms at the $\mathrm{C}_{\alpha}$-position of the Th ring. These shoulder are not observed for the $\mathrm{PTh}_{3}{ }^{*}-g-\mathrm{PEG}_{2000}$ copolymers. The peak at $791 \mathrm{~cm}^{-1}$ corresponds to the $\mathrm{C}_{\beta}-\mathrm{H}$ out of plane bending modes. The absorption intensity at $1630 \mathrm{~cm}^{-1}$ has been attributed to the $\mathrm{C}=\mathrm{C}$ stretching vibration of the $\mathrm{Th}$ ring, reflecting the conjugation behavior of the polyaromatic backbone. On the other hand, the band at $1120 \mathrm{~cm}^{-1}$ corresponds to the $\mathrm{ClO}_{4}^{-}$dopant agent.

The PEG component absorptions, which are similar to those reported for $\mathrm{PTh}_{5^{-}} g_{-}$ $\mathrm{PEG}_{2000}{ }^{20}$ appear at $2925 \mathrm{~cm}^{-1}$ (antisymmetric $\left.\mathrm{CH}_{3}\right), 1402$ and $1327 \mathrm{~cm}^{-1}\left(\mathrm{CH}_{2}\right.$ wagging), $1265 \mathrm{~cm}^{-1}\left(\mathrm{CH}_{2}\right.$ twisting) and $1160 \mathrm{~cm}^{-1}$ (vCO). The peak associated to the 
$\mathrm{C}=\mathrm{O}$ group of the ester linkage between the conjugated PTh chain and the PEG chain has been identified at $1728 \mathrm{~cm}^{-1}$. This peak is more intense for the 75:25 copolymer than for the 50:50 one, proving that the former contains the highest content of polymerized $\mathrm{Th}_{3}-\mathrm{PEG}_{2000}$ macromonomer. This feature is fully consistent with the intensity of the antisymmetric $\mathrm{CH}_{3}$ band at $2925 \mathrm{~cm}^{-1}$, which is also higher for the 75:25 copolymer.

In order to obtain a rough estimation of the composition of the two prepared $\mathrm{PTh}_{5^{-}} g_{-}$ $\mathrm{PEG}_{2000}$ copolymers, the ratios of the areas associated to the absorptions band at 2925 $\mathrm{cm}^{-1}$ (antisymmetric $\left.\mathrm{CH}_{3}\right)$ and $1630 \mathrm{~cm}^{-1}(\mathrm{C}=\mathrm{C}$ stretching vibration of the Th ring) were evaluated. Results indicate that the copolymers derived from 50:50 and 75:25 $\mathrm{Th}_{3^{-}}$ $\mathrm{PEG}_{2000}: \mathrm{Th}_{3}$ weight ratios present, respectively, $\sim 4$ and $\sim 2 \mathrm{Th}_{3}$ units per $\mathrm{Th}_{3}-\mathrm{PEG}_{2000}$ unit. This estimation is in good agreement with previously discussed XPS observations. Unfortunately, the insolubility of the copolymers precludes a more quantitative determination of their final composition by other techniques, as for example NMR.

\section{Surface properties}

The surface morphology of $\mathrm{PTh}_{3}{ }^{*}-g-\mathrm{PEG}_{2000}$ and $\mathrm{PTh}_{3}$ films was examined by SEM (Figure 2). Low and medium resolution micrographs reveal the formation of agglomerates onto the surface of $\mathrm{PTh}_{3}{ }^{*}-g-\mathrm{PEG}_{2000}$ films, perturbing the very compact aspect detected at the level surface of graft copolymer films. The frequency and dimensions of these aggregates increase with the content of $\mathrm{Th}_{3}$ in the generation medium, which is corroborated by examining the surface morphology of $\mathrm{PTh}_{3}$ films (Figure 2). Thus, $\mathrm{PTh}_{3}$ shows a very high concentration of large aggregates at the surface. High resolution SEM micrographs (Figure 2) indicate that the texture of these 
aggregates is similar to that of the leveled surface for $\mathrm{PTh}_{3}$. In contrast, the textures of the leveled surface and the aggregates deposited onto it are very different for $\mathrm{PTh}_{3}{ }^{*}-g$ $\mathrm{PEG}_{2000}$ films, this feature being especially remarkable for copolymer derived from the $75: 25$ ratio.

2D and 3D AFM height images are displayed in Figure 3. The topography of the 75:25 $\mathrm{PTh}_{3}{ }^{*}-g-\mathrm{PEG}_{2000}$ film consists on a distribution of sharp, narrow and relatively low peaks. Both the width and height of these peaks increase significantly in the 50:50 $\mathrm{PTh}_{3}{ }^{*}-g-\mathrm{PEG}_{2000}$ film, which has been attributed to the incorporation of the $\mathrm{Th}_{3}$ macromonomers. This provokes a significant enhancement of the RMS roughness $(\mathrm{Rq})$, which increases from $56 \pm 35$ to $74 \pm 15 \mathrm{~nm}$ with the concentration of $\mathrm{Th}_{3}$ in the generation medium. These features are magnified in $\mathrm{PTh}_{3}$ films, which show not only the widest and highest peaks but also an $\mathrm{Rq}=137 \pm 52 \mathrm{~nm}$. These results, which are in very good agreement with previous SEM observations, suggest that $\mathrm{Th}_{3}$ units do not incorporate homogeneously. Indeed, the roughness determined for $\mathrm{PTh}_{5}-g-\mathrm{PEG}_{2000}$ films was of only $\mathrm{Rq}=12.1 \pm 2.1 \mathrm{~nm}$.

Contact angle values determined for 50:50 $\mathrm{PTh}_{3}{ }^{*}-g-\mathrm{PEG}_{2000}$ and $\mathrm{PTh}_{3}$ are $90^{\circ} \pm 4^{\circ}$ and $89^{\circ} \pm 2^{\circ}$, respectively, evidencing the hydrophobic nature of the thiophene rings. These values suggest that the 50:50 copolymer incorporates a high amount of $\mathrm{Th}_{3}$ at the latter steps of the electrochemical polymerization process, hydrophilic PEG chains remaining inside the films. Accordingly, contact angle measurements, which provide information about the hydrophilic or hydrophobic behavior at the surface, evidence that both 50:50 $\mathrm{PTh}_{3}{ }^{*}-g-\mathrm{PEG}_{2000}$ and $\mathrm{PTh}_{3}$ surfaces contain similar distributions of similar polyconjugated chains. In contrast, the contact angle obtained for 75:25 $\mathrm{PTh}_{3}{ }^{*}-g$ $\mathrm{PEG}_{2000}, 67^{\circ} \pm 5^{\circ}$, indicates an enhancement of the surface hydrophilicity due the PEG 
chains. The contact angle reported for $\mathrm{PTh}_{5^{-}} g-\mathrm{PEG}_{2000}, 76^{\circ} \pm 5^{\circ},{ }^{22}$ is intermediate between those measured for 75:25 and 50:50 $\mathrm{PTh}_{3}{ }^{*}-g-\mathrm{PEG}_{2000}$ films.

\section{Optical and electrochemical properties}

Figure 4a compares the UV-vis spectra of 75:25 and 50:50 $\mathrm{PTh}_{3}{ }^{*}-g-\mathrm{PEG}_{2000}$. The shapes of the two spectra are similar, showing a broad absorption band with $\lambda_{\max }$ at 458 and $501 \mathrm{~nm}$, respectively. This band, which corresponds to the $\pi-\pi^{*}$ transition, have been used to approximate the optical $\pi-\pi^{*}$ lowest transition energy $\left(\mathrm{E}_{\mathrm{g}}\right)$ by estimating the onset wavelength $\left(\lambda_{\text {onset }}=573\right.$ and $566 \mathrm{~nm}$ for the 75:25 and 50:50 copolymer respectively), the resulting values being 2.16 (75:25) and $2.19 \mathrm{eV}$ (50:50). These $\mathrm{E}_{\mathrm{g}}$ gaps are slightly lower than those reported for $\mathrm{PTh}_{5^{-}} g-\mathrm{PEG}_{1000}$ and $\mathrm{PTh}_{5^{-}} g-\mathrm{PEG}_{2000}$ doped with $\mathrm{ClO}_{4}^{-}$(2.25 and $2.29 \mathrm{eV}$, respectively), which were estimated using the same methodology. ${ }^{22}$ Accordingly, the $\pi$-electron delocalization in graft copolymers made of PTh and PEG increases with decreasing PEG / Th ratio.

The UV-vis spectrum recorded for $\mathrm{PTh}_{3}$ is included in Figure $4 \mathrm{a}$. The $\mathrm{E}_{\mathrm{g}}$ estimated for $\pi-\pi^{*}$ lowest transition energy $\left(\lambda_{\max }=458 \mathrm{~nm}\right)$ is $2.28 \mathrm{eV}\left(\lambda_{\text {onset }}=543 \mathrm{~nm}\right)$. This gap is higher than those described for PTh derivatives with small substituents at the $\beta$-position (e.g. poly(thiophene-3-methyl acetate), 1.98-2.17 eV; ${ }^{26}$ poly(3-chlorothiophene), 2.14 $\mathrm{eV} ;{ }^{27}$ and poly(3-bromothiophene), $1.93-1.97 \mathrm{eV}^{28}$ ). This feature suggests that $\mathrm{Th}_{3}$ repeat units may polymerize forming $\alpha-\beta$ and/or $\beta-\beta$ linkages in addition to the expected $\alpha-\alpha$ linkages. On the other hand, the $\mathrm{PTh}_{3}$ spectrum shows a broad absorption tail between $\sim 500$ and $\sim 700 \mathrm{~nm}$ ascribed to the polaronic band of the conductive 
quinoid form. This is considerably smaller for the 50:50 graft copolymer and practically inappreciable for the 75:25 one.

Figure $4 \mathrm{~b}$ compares the cyclic voltammograms recorded for $\mathrm{PTh}_{3}{ }^{*}-g-\mathrm{PEG}_{2000}$ and $\mathrm{PTh}_{3}$. The 75:25 $\mathrm{PTh}_{3}{ }^{*}-g-\mathrm{PEG}_{2000}$ copolymer shows the highest electrochemical activity (electroactivity), which refers to the ability to exchange charge reversibly and increases with the similarity between the anodic and cathodic areas. Thus, the electroactivity of $\mathrm{PTh}_{3}$ and 50:50 $\mathrm{PTh}_{3}{ }^{*}-g-\mathrm{PEG}_{2000}$ is around $30 \%$ and 20\% lower than that of the 75:25 graft copolymer. This feature may be attributed to two different reasons: (1) the conjugation length in $\mathrm{PTh}_{3}$ is relatively small due to the formation of cross-linking (i.e. polymer chains grow not only through $\alpha$ - $\alpha$ linkages between units but also through $\alpha-\beta$ and $\beta-\beta$ linkages); and/or (2) the structure becomes more compact with increasing amount of $\mathrm{Th}_{3}$ units, making more difficult the access and escape of the dopant ions into the dopant ions during the redox processes.

The degree of cross-linking is typically determined by the number of electrons consumed to incorporate a monomer into the polymer and to oxidize the resulting chain $\left(n_{\mathrm{ox}}\right)$, this information being determined through the electropolymerization kinetics (i.e. by considering different polymerization for the generation of polymer films under a constant potential). ${ }^{29,31}$ After discounting the oxidation charge used to compensate the charge of the dopant ion (i.e. doping level), the average number of electrons per monomer $\left(n_{\mathrm{av}}\right)$ incorporated into a linear polymer chain obtained from a typical condensation should be $n_{\mathrm{av}} \approx 2.0$ (i.e. two protons and two electrons are involved in the formation of the $\alpha-\alpha$ bond between the terminal repeat unit of the chain and the incorporated monomer. ${ }^{29,31}$ Thus, cross-links are proved when $n_{\mathrm{av}}>2.0$.

The value of $n_{\mathrm{ox}}$ for $\mathrm{PTh}_{3}$ has been determined using the following equation: ${ }^{29-31}$ 


$$
n_{\mathrm{ox}}=\frac{M Q_{\mathrm{pol}}}{F W_{\mathrm{ox}}\left(1-W_{\mathrm{dop}}\right)}
$$

where $M$ is the molar mass of $\mathrm{PTh}_{3}, Q_{\mathrm{pol}}$ is the polymerization charge consumed in each process (in $\mathrm{mC} / \mathrm{cm}^{2}$ ) calculated from the chronoamperograms, $\mathrm{F}$ is the Faraday constant, $W_{\text {ox }}$ is the film weight (in $\mathrm{mg} / \mathrm{cm}^{2}$ ) and $W_{\text {dop }}$ is the mass of $\mathrm{ClO}_{4}^{-}$per polymer unit of mass. The doping level (dl) of $\mathrm{PTh}_{3}$ and, therefore, $W_{\text {dop }}$ were estimated electrochemically using the following equation:

$$
\mathrm{dl}=\frac{2 Q_{0}}{Q_{D}-Q_{0}} \times 100
$$

where $\mathrm{Q}_{\mathrm{D}}$ is the total charge used for the nanocomposite deposition and $Q_{0}$ is the total charge of oxidized species in the nanocomposite films. The value of $\mathrm{dl}$ is used to obtain $n_{\mathrm{av}}:$

$$
n_{\mathrm{av}}=n_{\mathrm{ox}}-\mathrm{dl}
$$

The electrochemical doping level for $\mathrm{PTh}_{3}$ is 0.12 , this value being even lower than that roughly estimated by $\mathrm{EDX}$ (i.e. 0.23 ). This corresponds to a $\mathrm{ClO}_{4}^{-}$molecule every $\sim 8.3 \mathrm{Th}_{3}$ repeat units (i.e. every 25 thiophene rings). On the other hand, the values of $n_{\mathrm{ox}}$ and $n_{\mathrm{av}}$ are 2.08 and 1.96 , respectively. This feature indicates that the $\mathrm{PTh}_{3}$ matrix is formed by linear chains in which $\mathrm{Th}_{3}$ units are attached though $\alpha-\alpha$ linkages.

The porosity of $\mathrm{PTh}_{3}{ }^{*}-g-\mathrm{PEG}_{2000}$ and $\mathrm{PTh}_{3}$ was quantified through the parameter $\Delta,{ }^{32}$ which is calculated as follows:

$$
\Delta=\frac{\ell_{0}-\ell_{10}}{\ell_{0}} \times 100
$$

where $\ell_{0}$ and $\ell_{10}$ refer to the thickness before applying any redox cycle (as prepared samples) and after 10 consecutive oxidation-reduction cycles, respectively. Although all 
samples experience a reduction after 10 redox cycles (ESI), the porosity being significantly higher for the graft copolymers $(\Delta=18.9 \%$ and $14.8 \%$ for $75: 25$ and $50: 50$ $\mathrm{PTh}_{3}{ }^{*}-g-\mathrm{PEG}_{2000}$, respectively) than for $\mathrm{PTh}_{3}(\Delta=7.1 \%)$. This remarkable difference, which explains the higher ability to store charge of the copolymers, should be attributed to the molecular architecture of $\mathrm{PTh}_{3}{ }^{*}-g-\mathrm{PEG}_{2000}$ and $\mathrm{PTh}_{3}$. Thus, $\mathrm{PTh}_{3}$ forms linear chains that adopt a compact aligned disposition due to the geometric constraints associated to the heterocyclic rings. ${ }^{33}$ In contrast, the grafted architecture of $\mathrm{PTh}_{3}{ }^{*}-g$ $\mathrm{PEG}_{2000}$ molecules, in which PEG side chains present coiled or extended conformations depending on environment ${ }^{22}$ while PTh backbones adopt a linear disposition, favors an organization with cavities. The cavities of these porous matrices tend to disappear upon aggressive consecutive oxidation-reduction cycles, provoking a significant reduction in the thickness of the films (ESI).

The electrochemical stability (electrostability), which has been evaluated through the loss of electroactivity (LEA) against the number of oxidation-cycles (ESI), decreases with the oxidation and reduction areas of consecutive control voltammograms. Cyclic voltammograms recorded after 10 consecutive oxidation-reduction cycles (ESI) results in LEA values of $25 \%$ and $15 \%$ for the $75: 25$ and 50:50 copolymers, and of $35 \%$ for $\mathrm{PTh}_{3}$. Thus, the compactness of the films increases with the number of redox cycles and, therefore, the access and escape of dopant anions into the polymeric matrix become less favored when the number of these Faradaic processes increases. In spite of this, the most stable material after 10 redox cycles is the $75: 25 \mathrm{PTh}_{3}{ }^{*}-g-\mathrm{PEG}_{2000}$ copolymer, the electroactivities of 50:50 $\mathrm{PTh}_{3}{ }^{*}-g-\mathrm{PEG}_{2000}$ and $\mathrm{PTh}_{3}$ being very similar and $20 \%$ smaller. It is worth nothing that the LEA measured for $\mathrm{PTh}_{5}-g-\mathrm{PEG}_{2000}$ after 10 redox 
cycles was of $35 \% .^{22}$ Accordingly, the latter is less electrostable than $75: 25 \mathrm{PTh}_{3}{ }^{*}-g$ $\mathrm{PEG}_{2000}$.

\section{Cytotoxicity}

The potential cytotoxicity of $\mathrm{PTh}_{3}{ }^{*}-g-\mathrm{PEG}_{2000}$ and $\mathrm{PTh}_{3}$ was elucidated by culturing Cos-7 cells in plate wells containing steel sheets covered by these organic materials. Cytotoxicity was determined after $24 \mathrm{~h}$ using the MTT assay and quantifying all viable cells contained in the wells, which allowed us to consider the toxic effects associated not only to the polymeric matrix but to small molecules (e.g. acetonitrile, monomer and dopant molecules) or oligomers that could be eventually released from the polymeric matrix. Results displayed in Figure 5 reflect the cytotoxic effects of $\mathrm{PTh}_{3}$, which reduce cells viability about $50 \%$ with respect TCP and steel controls. In contrast, these negative effects are not observed for 75:25 and 50:50 copolymers that show viabilities slightly higher than those of the controls This behavior should be attributed to, monomers, small oligomers and medium size harmful molecules that are leaching out from the $\mathrm{PTh}_{3}$ films. This phenomenon does not occur in $\mathrm{PTh}_{3}{ }^{*}-g-\mathrm{PEG}_{2000}$ matrices because the size and flexibility of PEG side chains contribute to the immobilization of such medium size components, making difficult or even precluding their delivery to the medium.

In order to check if monomers and small oligomers, which are typically retained in a small fraction within polymeric matrices, may affect the cellular viability if they are released to the culture medium, toxicity curves were determined for Cos-7 cells cultured in presence of the $\mathrm{Th}_{3}$ monomer during $24 \mathrm{~h}$. Results, which are displayed in Figure 6, were obtained by subtracting the toxic effect of the acetonitrile solvent from the curve of the monomer to obtain reliable information about its own toxicity. As it can be seen, 
the maximum of toxicity is reached when the concentration of $\mathrm{Th}_{3}$ is around $5 \times 10^{-5} \mathrm{M}$ becoming stable at higher concentrations. The overall of the results obtained in this subsection demonstrates that Cos-7 cells can be cultured on the $\mathrm{PTh}_{3}{ }^{*}-g-\mathrm{PEG}_{2000}$ copolymers because the PEG chains avoids the exposition of the cells to concentrations of monomer and small oligomer large enough to affect their viability. Unfortunately, this is not possible for possible in $\mathrm{PTh}_{3}$, which requires from alternative strategies, like that described below, to avoid the release of the entrapped toxic compounds.

\section{Cellular adhesion and proliferation}

The biocompatibility of $\mathrm{PTh}_{3}{ }^{*}-g-\mathrm{PEG}_{2000}$ and $\mathrm{PTh}_{3}$ was examined by comparing the abilities of these organic matrices to enhance cellular adhesion and proliferation onto the prepared films. In this case steel was considered as the control substrate since polymeric films were directly deposited on this material. Quantitative results for cellular adhesion are displayed in Figure 7a. As expected, cellular adhesion onto $\mathrm{PTh}_{3}$ is severely conditioned by the cytotoxicity of this matrix (Figure 5), relatively viability of Cos-7 cells onto the film after $24 \mathrm{~h}$ being very low ( $\sim 30 \%)$. In opposition, quantification of cell adhesion onto 75:25 and 50:50 $\mathrm{PTh}_{3}{ }^{*}-g-\mathrm{PEG}_{2000}$ films reveals activities of $60 \%$ and $70 \%$, respectively, which are higher than those of the steel control substrate.

Cell adhesion affects cell proliferation (Figure 7b), the number of cells on the surface of the films after $72 \mathrm{~h}$ being significantly higher for the two graft copolymers $(\sim 70 \%)$ than for $\mathrm{PTh}_{3}(\sim 25 \%)$. Indeed, the relative viability per unit of area determined for steel $(\sim 50 \%)$ is also significantly higher than for $\mathrm{PTh}_{3}$. These results support the negative effect associated to the release of medium size oligomers from the $\mathrm{PTh}_{3}$ matrix. Comparison of these results with those reported for $\mathrm{PTh}_{5^{-}} g-\mathrm{PEG}_{2000}{ }^{22}$ reveals that 
$\mathrm{PTh}_{3}{ }^{*}-g-\mathrm{PEG}_{2000}$ is more biocompatible. Thus, the relative viabilities determined for $\mathrm{PTh}_{5}-g-\mathrm{PEG}_{2000}$ using steel as the control reference are $\sim 60 \%$ and $\sim 65 \%$ for cellular adhesion and proliferation assays, respectively. The biocompatibility of $\mathrm{PTh}_{n}$ - $g$-PEG increases with decreasing PEG / Th ratio. Although PEG is a well-known biocompatible polymer, ${ }^{34,35}$ the ion exchange ability of the electroactive backbone also plays a crucial role. Therefore, the biocompatibility of $\mathrm{PTh}_{n}-g$-PEG results from the balance between the benefits induced by the PEG side chains and the length of the PTh backbone.

\section{Electrocompatibility}

Control voltammograms of $\mathrm{PTh}_{3}{ }^{*}-g-\mathrm{PEG}_{2000}$ and $\mathrm{PTh}_{3}$ coated with Cos-7 cells are displayed in Figure 8a. Comparison with the voltammograms recorded for the uncoated films (Figures 4b) indicates that cells provoke in all cases a significant increase of the maximum value of anodic current density $\left(j_{\max }\right)$, which corresponds to that obtained at the reversal potential. More specifically, $j_{\max }$ increases from $0.38 / 0.24$ to $0.74 / 0.55$ $\mathrm{mA} / \mathrm{cm}^{2}$ for 75:25 / 50:050 copolymer films and from 0.21 to $0.47 \mathrm{~mA} / \mathrm{cm}^{2}$ for $\mathrm{PTh}_{3}$. Moreover, Cos-7 cells enhance considerably the ability of $\mathrm{PTh}_{3}{ }^{*}-g-\mathrm{PEG}_{2000}$ and $\mathrm{PTh}_{3}$ films to store charge, even though electroactivity follows the same relative order that without cells: 75:25 copolymer $>$ 50:50 copolymer $>\mathrm{PTh}_{3}$. The electroactivity of $\mathrm{PTh}_{3}{ }^{*}-g-\mathrm{PEG}_{2000}$ and $\mathrm{PTh}_{3}$ increases $\sim 165 \%$ and $\sim 120 \%$, respectively, upon coating will cells. This feature is consistent with the exchange of ions between the PTh-containing matrix and the cells.

Application of consecutive oxidation-reduction cycles led to a reduction of the electroactivity in all cases, as is clearly reflected in the voltammograms recorded after 10 redox cycles (Figure 8b). Thus, the electroactivity of the 75:25 and 50:50 
copolymers and $\mathrm{PTh}_{3}$ cells coated with cells underwent a reduction of $\mathrm{LEA}=22 \%, 18 \%$ and $6 \%$, respectively, after 10 cycles. In spite of this, it is worth noting that the electroactivity of polymeric films coated with cells when submitted to 10 redox cycles is around $85 \%-100 \%$ higher than the electroactivity of as prepared films without cells. Accordingly, application of oxidation and reduction potentials to cells does not provoke a moderate reduction of the benefits induced by such living systems, the electrochemical behavior of coated films being better than that of films without cells.

These results evidence that the ability to exchange charge reversibly of the three coated materials depends on the interactions at the interface between the surface of the substrate and the cellular monolayer. This feature, which occurs similarly for 75:25 and 50:50 $\mathrm{PTh}_{3^{-}}$- $\mathrm{PEG}$ and $\mathrm{PTh}_{3}$, suggests that the contribution of polymer-cell interactions is more important than the chemical nature and intrinsic properties of the polymeric material.

\section{Cytotoxicity and cellular adhesion of $\mathrm{PTh}_{3}{ }^{*}-\mathrm{g}-\mathrm{PEG}_{\mathbf{2 0 0 0}} /$ collagen platforms}

Protein adsorption onto surfaces is the first stage that takes place in cell adhesion and proliferation processes when biomaterials contact living cells in the appropriated media. Type I collagen is the most common collagen isotype. In addition, type I collagen is one of the most abundant extra cellular matrix (ECM) proteins, which is known to bind fibronectin, another important ECM protein, for early adhesion. ${ }^{36}$ The cellular response of polymeric materials has been shown to be influenced by the adsorption of collagen onto their surface. ${ }^{37-39}$ In order to look for an improvement in the properties of $\mathrm{PTh}_{n^{-}} \mathrm{g}_{\text {- }}$ PEG as bioactive platforms, in this work collagen has been adsorbed onto the surface of $\mathrm{PTh}_{3}{ }^{*}-g-\mathrm{PEG}_{2000}$ and $\mathrm{PTh}_{3}$ films using the procedure described in the Methods section. 
The cytotoxicity of $\mathrm{PTh}_{3}{ }^{*}-g-\mathrm{PEG}_{2000} /$ collagen and $\mathrm{PTh}_{3} /$ collagen was evaluated through viability assays, as those described above, using Cos-7 cells. Results (Figure 9) indicate that collagen does not improve appreciably the cell viability of $\mathrm{PTh}_{3}{ }^{*}-g$ $\mathrm{PEG}_{2000}$ copolymers, which was found to be relatively high for films without superficially absorbed protein (Figure 5). However, a very noticeable result is that adsorbed collagen inhibits the cytotoxicity of $\mathrm{PTh}_{3}$ films, the relatively viability of $\mathrm{PTh}_{3}$ / collagen being practically identical to those of $\mathrm{PTh}_{3}{ }^{*}-g-\mathrm{PEG}_{2000}$ and $\mathrm{PTh}_{3}{ }^{*}-g-\mathrm{PEG}_{2000}$ / collagen. This result corroborates that the cytotoxicity of $\mathrm{PTh}_{3}$ is due to the release of medium size harmful molecules from the polymeric matrix to the culture medium. This phenomenon is precluded in $\mathrm{PTh}_{3} /$ collagen by the layer of protein deposited onto the polymeric surface, which acts as a stopper.

Finally, the fibrous protein matrix on the top layer of $\mathrm{PTh}_{3}{ }^{*}-g-\mathrm{PEG}_{2000} /$ collagen and $\mathrm{PTh}_{3} /$ collagen favors cellular adhesion (Figure 10) with respect to that observed for same organic films but without protein coating (Figure 5). As expected, the increment is higher for $\mathrm{PTh}_{3}(\sim 30 \%)$ than for the graft copolymers $(<20 \%)$ because of the inhibition of cytotoxic effects in the former. These results allow us to conclude that, although the cellular response of bioactive platforms based graft copolymers with electroactive and hydrophilic characteristics is intrinsically very good, it can be easily enhanced by adding a top collagen layer. Thus, the role of this absorbed bio-layer is not only to enhance cell growth but also to act as a stopper, preventing eventual cytotoxic effects associated to the delivery of harmful molecules.

\section{CONCLUSIONS}


$\mathrm{PTh}_{3}{ }^{*}-g$-PEG graft copolymers have been prepared by anodic copolymerization using a mixture of $\mathrm{Th}_{3}$-PEG and $\mathrm{Th}_{3}$ macromonomers. Although determination of the final composition is a very difficult task because of the insolubility of the copolymers, qualitative estimations obtained by FTIR suggest that materials derived from 50:50 and 75:25 $\mathrm{Th}_{3}-\mathrm{PEG}_{2000}: \mathrm{Th}_{3}$ feeding compositions present $\sim 4$ and $\sim 2 \mathrm{Th}_{3}$ units per $\mathrm{Th}_{3^{-}}$ $\mathrm{PEG}_{2000}$ unit, respectively. The optical $\left(\mathrm{E}_{\mathrm{g}}\right)$ and electrochemical (electroactivity and electrostability) properties of these graft copolymers have found to be better than those of $\mathrm{PTh}_{5^{-}} g$-PEG and $\mathrm{PTh}_{3}$. This behavior has been attributed to a combination of two factors: (1) conjugated chains are longer in $\mathrm{PTh}_{3}{ }^{*}-g$-PEG than in $\mathrm{PTh}_{5}-g$-PEG; and (2) the porosity of graft copolymers facilitates the access and escape of dopant ions during Faradaic processes, which is not possible in compact structures formed by linear $\mathrm{PTh}_{3}$ chains.

Analyses of cytotoxicity, cellular adhesion and proliferation and electrocompatibility of polymeric substrates covered by cells reveal that the behavior of $\mathrm{PTh}_{3}{ }^{*}-$ $g$-PEG as bioactive platform is better than those of $\mathrm{PTh}_{5^{-}} g$-PEG and $\mathrm{PTh}_{3}$. More specifically, $\mathrm{PTh}_{3}$ has been found to be cytotoxic, which have been attributed to the release of medium size harmful molecules from the polymeric matrix to the culture medium. Cellular adhesion and proliferation on the surface of graft copolymers have been found to increase with decreasing PEG / PTh ratio, while the biocompatibility of $\mathrm{PTh}_{3}$ is very low because of its cytotoxic effects. $\mathrm{PTh}_{3}{ }^{*}-g$-PEG copolymers have shown the highest electro-compatibility with cells. Thus, the electroactivity and electrochemical stability of $\mathrm{PTh}_{3}{ }^{*}-g$-PEG coated with cells have been found to be significantly higher not only than those of all other examined substrates with and without cells but also than those of uncoated $\mathrm{PTh}_{3}{ }^{*}-g$-PEG. Finally, the noxious 
cytotoxic effects of $\mathrm{PTh}_{3}$ have been eliminated by incorporating a thin layer of collagen adsorbed onto the polymeric matrix, which acts as a stopper and enables cellular adhesion.

In summary, the behavior of $\mathrm{PTh}_{3}{ }^{*}-g$-PEG copolymers, especially the $75: 25$, as electroactive substrates for biomedical applications is very good. Thus, these hydrophilic materials promote cell growth and are electro-compatible will cells. Current research is oriented towards cell regeneration onto 75:25 $\mathrm{PTh}_{3}{ }^{*}-\mathrm{g}$-PEG bioactive substrates through electrical stimulation for different advanced biomedical applications.

\section{ACKNOWLEDGEMENTS}

This work has been supported by MICINN and FEDER funds (project number MAT2012-34498), the DIUE of the Generalitat de Catalunya (contracts number 2009SGR925 and XRQTC). G.F. is thanked by her FPI-UPC grant. Support for the research of C.A. was received through the prize "ICREA Academia" for excellence in research funded by the Generalitat de Catalunya. Two of the authors (A-D. B. and I.C.) acknowledge the financial support given by European Social Fund "Cristofor I. Simionescu" Postdoctoral Fellowship Programme (ID POSDRU/89/1.5/S/55216), Sectorial Operational Programme Human Resources Development 2007-2013.

\section{REFERENCES}

1. C. Feng, Y. J. Li, D. Yang, J. H. Hu, X. H. Zhang, X. Y. Huang, Chem. Soc. Rev. 2011, 3, 1282-1295.

2. D. Neugebauer, Polym. Int. 2007, 56, 1469-1498.

3. H. G. Borner, K. Matyjaszewski, Macromol. Symp. 2002, 177, 1-15. 
4. $\quad$ K. Nomura, M. M. Abdellatif, Polymer 2010, 51, 1861-1881.

5. M. Zhang, A. H. E. Muller, J. Polym. Sci.: Part A: Polym. Chem. 2005, 43, $3461-3481$.

6. S. S. Sheiko, B. S. Sumerlin, K. Matyjaszewski, Prog. Polym. Sci. 2008, 33, $759-785$.

7. H. Leea, J. Pietrasik, S. S. Sheiko, K. Matyjaszewski, Prog. Polym. Sci. 2010, $35,24-44$.

8. J. Rzayev, ACS Macro Lett. 2012, 1, 1146-1149.

9. I. Cianga, Y. Yagci, Prog. Polym. Sci. 2004, 29, 387- 399.

10. E. H.Kang, I. H. Lee, T. L Choi, ACS Macro Lett. 2012, 1, 1098-1102.

11. J. Shen, K. Ogino, Chem. Lett. 2005, 34, 1616-1617.

12. J. Shen, K. Tsuchiya, K. Ogino, J. Polym. Sci., Part A: Polym. Chem. 2008, 46, 1003-1013.

13. P. J. Costanzo, K. K. Stokes, Macromolecules 2002, 35, 6804-6810.

14. L. Qi, M. Sun, S. Dong, J Appl Polym Sci 2006, 102, 1803-1808.

15. S. S. Balamurugan, G. B. Bantchev, Y. Yang, R. L. McCarley, Angew. Chem. Int. 2005, 44, 4872-4876.

16. S. Das, S. Samanta, D. P. Chatterjee, A. K. Nandi, J. Polym. Sci., Part A: Polymer Chem. 2013, 51, 1417-1427.

17. X. Chen, B. Gholamskhass, X. Han, G. Vamvouinis, S. Holdcro, Macromol. Rapid Commun. 2007, 28, 1792-1797.

18. C. D. Grande, M. C. Tria, G. Jiang, R. Ponnapati, R. Advincula, Macromolecules 2011, 44, 966- 975. 
19. L. Strover, C. Roux, J. Malmström, Y. Pei, D. E. Williams, J. Travas-Sejdic, Synth. Met. 2012, 162, 381-390.

20. A. D. Bendrea, G. Fabregat, L. Cianga, F. Estrany, L. J. del Valle, I. Cianga, C. Alemán, Polym. Chem. 2013, 4, 2709-2723.

21. A. D. Bendrea, L. Cianga, E. G. Hitruc, I. Titorencu, I. Cianga, Materiale Pastice 2013, 2, 71-78.

22. A. D. Bendrea, G. Fabregat, J. Torras, S. Maione, L. Cianga, L. J. del Valle, I. Cianga, C. Alemán, J. Mater. Chem. B 2013, 1, 4135-4145.

23. G. Fabregat, G. Ballano, E. Armelin, L. J. del Valle, C. Cativiela, C. Alemán, Polym. Chem. 2013, 4, 1412-1424.

24. A.-D. Bendrea, L. Cianga, I. Cianga, Rev. Roum. Chim., 2013, 58, 153-160.

25. T. Mosmann, J. Immunol. Methods 1983, 65, 55-63.

26. A. L. Gomes, J. Casanovas, O. Bertran, J. S. de C. Campos, E. Armelin, C. Alemán, J. Polym. Res. 2011, 18, 1509-1517.

27. Y. Pang, X. Li, G. Shi, L. Jin, Thin Solid Films 2008, 516, 6512-6516.

28. J. Casanovas, D. Aradilla, J. Poater, M. Solà, F. Estrany, C. Alemán, Phys. Chem. Chem. Phys. 2012, 14, 10050-10062.

29. C. Ocampo, R. Oliver, E. Armelin, C. Alemán, F. Estrany, J. Polym. Res. 2006, $13,193-200$.

30. V. S. Vashanta, K. L. N. Phani, J. Electroanal. Chem. 2002, 520, 79-88.

31. D. Aradilla, D. S. Azambuja, F. Estrany, M. T. Casas, C. A. Ferreira, C. Alemán, J. Mater. Chem. 2012, 22, 13110-13122.

32. E. Pal, V. Hornok, D. Sebo, A. Majzik, Dekany, I. Colloids Surf. B 2010, 79, 276-283. 
33. C. Alemán, D. Curcó, J. Comput. Chem. 2007, 28, 1743-1749.

34. S. P. Zhong, Y. P. Zhang, C. T. Lim, Tissue Engin. Part B-Reviews 2012, 18, 77-87.

35. C. Mangold, F. Wurm, H. Frey, Polym. Chem. 2012, 3, 1714-1721.

36. J. S. Tjia, B. J. Aneskievich, P. V. Moghe, Biomaterials 1999, 20, 2223-2233.

37. N. M. Coelho, C. González-García, M. Salmerón-Sánchez, G. Altankov, Biotechnol. Bioeng. 2011, 108, 3009-3018.

38. N. M. Coelho, M. Salmeron-Sanchez, G. Altankov, Biomater. Sci. 2013, 1, 494502.

39. M. M. Pérez-Madrigal, M. I. Giannotti, L. J. del Valle, L. Franco, E. Armelin, J. Puiggalí, F. Sanz and C. Alemán, ACS Appl. Mater. Interf. 2014 in press (DOI: 10.1021/am502150q). 


\section{CAPTIONS TO FIGURES}

Figure 1. FTIR spectra of $\mathrm{PTh}_{3}{ }^{*}-g-\mathrm{PEG}_{2000}\left(75: 25\right.$ and 50:50 $\left.\mathrm{Th}_{3}-g-\mathrm{PEG}_{2000}: \mathrm{Th}_{3}\right)$ and $\mathrm{PTh}_{3}$.

Figure 2. Low, medium and high resolution SEM micrographs of $\mathrm{PTh}_{3}{ }^{*}-g-\mathrm{PEG}_{2000}$ (75:25 and 50:50 $\mathrm{Th}_{3^{-}} g-\mathrm{PEG}_{2000}: \mathrm{Th}_{3}$ ) and $\mathrm{PTh}_{3}$.

Figure 3. AFM height image of $\mathrm{PTh}_{3}{ }^{*}-g-\mathrm{PEG}_{2000}\left(75: 25\right.$ and $\left.50: 50 \mathrm{Th}_{3}-g-\mathrm{PEG}_{2000}: \mathrm{Th}_{3}\right)$ and $\mathrm{PTh}_{3}$.

Figure 4. (a) UV-vis spectra and (b) cyclic voltammograms in $\mathrm{PBS}$ of $\mathrm{PTh}_{3}{ }^{*}-g-\mathrm{PEG}_{2000}$ (75:25 and 50:50 $\mathrm{Th}_{3}-g-\mathrm{PEG}_{2000}: \mathrm{Th}_{3}$ ) and $\mathrm{PTh}_{3}$ doped with $\mathrm{ClO}_{4}^{-}$.

Figure 5. Cytotoxycity of $\mathrm{PTh}_{3}{ }^{*}-g-\mathrm{PEG}_{2000}\left(75: 25\right.$ and 50:50 $\left.\mathrm{Th}_{3}-g-\mathrm{PEG}_{2000}: \mathrm{Th}_{3}\right)$ and $\mathrm{PTh}_{3}$ doped with $\mathrm{ClO}_{4}^{-}$. Three samples were analyzed for each group. Bars represent the mean standard deviation. The relative viability of Cos-7 cells was established in relation to the TCP control (tissue culture polystyrene). Steel was also considered as a control substrate because $\mathrm{PTh}_{3}{ }^{*}-g-\mathrm{PEG}_{2000}$ and $\mathrm{PTh}_{3}$ were deposited on this material. The asterisk $\left(^{*}\right)$ indicates a significant difference with the control, Tukey’s test $(p<0.05)$. Figure 6. Toxicity curve for Cos-7 cells of the $\mathrm{Th}_{3}$ monomer in acetonitrile. The toxicity of the solvent was subtracted from the cytotoxicity of the monomer. Four replicates were analyzed for each concentration of monomers after $24 \mathrm{~h}$ of culture. Each point represents the mean \pm standard error.

Figure 7. Cellular adhesion (a) and cellular proliferation (b) on $\mathrm{PTh}_{3}{ }^{*}-g-\mathrm{PEG}_{2000}(75: 25$ and 50:50 $\left.\mathrm{Th}_{3}-g-\mathrm{PEG}_{2000}: \mathrm{Th}_{3}\right)$ and $\mathrm{PTh}_{3}$ films. Three samples were analyzed for each group. Bars represent the mean standard deviation. The relative viability of Cos-7 cells was established in relation to the steel control, which was the substrate used to deposit 
the films. The asterisk $\left({ }^{*}\right)$ indicates a significant difference with the control, Tukey’s test $(p<0.05)$.

Figure 8. Cyclic voltammograms of $\mathrm{PTh}_{3}{ }^{*}-g-\mathrm{PEG}_{2000}\left(75: 25\right.$ and 50:50 $\mathrm{Th}_{3}-g-\mathrm{PEG}_{2000}$ : $\mathrm{Th}_{3}$ ) and $\mathrm{PTh}_{3}$ films coated with Cos-7 cells in PBS. Voltammograms of both the as prepared samples (a) and after ten consecutive oxidation-reduction cycles (b) are displayed.

Figure 9. Cytotoxycity of $\mathrm{PTh}_{3}{ }^{*}-g-\mathrm{PEG}_{2000}\left(75: 25\right.$ and 50:50 $\left.\mathrm{Th}_{3}-g-\mathrm{PEG}_{2000}: \mathrm{Th}_{3}\right)$ and $\mathrm{PTh}_{3}$ coated with a thin layer of adsorbed collagen. Three samples were analyzed for each group. Bars represent the mean standard deviation. The relative viability of Cos-7 cells was established in relation to the TCP control (tissue culture polystyrene). Steel was also considered as a control substrate because $\mathrm{PTh}_{3}{ }^{*}-g-\mathrm{PEG}_{2000}$ and $\mathrm{PTh}_{3}$ were deposited on this material. The asterisk $\left(^{*}\right)$ indicates a significant difference with the control, Tukey's test $(p<0.05)$.

Figure 10. Cellular adhesion (a) and cellular proliferation (b) on $\mathrm{PTh}_{3}{ }^{*}-g-\mathrm{PEG}_{2000}$ (75:25 and 50:50 $\left.\mathrm{Th}_{3}-g-\mathrm{PEG}_{2000}: \mathrm{Th}_{3}\right)$ and $\mathrm{PTh}_{3}$ films coated with a thin layer of adsorbed collagen. Three samples were analyzed for each group. Bars represent the mean standard deviation. The relative viability of Cos-7 cells was established in relation to the steel control, which was the substrate used to deposit the films. The asterisk $\left(^{*}\right)$ indicates a significant difference with the control, Tukey’s test $(p<0.05)$. 
Table 1. Atomic percent composition (C1s, O1s, Cl2p and S2p) obtained by XPS for 75:25 and 50:50 $\mathrm{PTh}_{3}{ }^{*}-g-\mathrm{PEG}_{2000}$ graft copolymers and $\mathrm{PTh}_{3}$.

\begin{tabular}{lllll}
\hline \multicolumn{1}{c}{ Sample } & $\mathrm{C} 1 \mathrm{~s}$ & $\mathrm{O} 1$ & $\mathrm{Cl} 2 \mathrm{p}$ & $\mathrm{S} 2 \mathrm{p}$ \\
\hline $\mathrm{PTh}_{3}{ }^{*}-g-\mathrm{PEG}_{2000}(75: 25)$ & 67.82 & 14.66 & 4.08 & 13.44 \\
$\mathrm{PTh}_{3}{ }^{*}-g-\mathrm{PEG}_{2000}(50: 50)$ & 72.44 & 9.12 & 2.43 & 16.01 \\
$\mathrm{PTh}_{3}$ & 66.70 & 12.49 & 3.87 & 16.94 \\
\hline
\end{tabular}




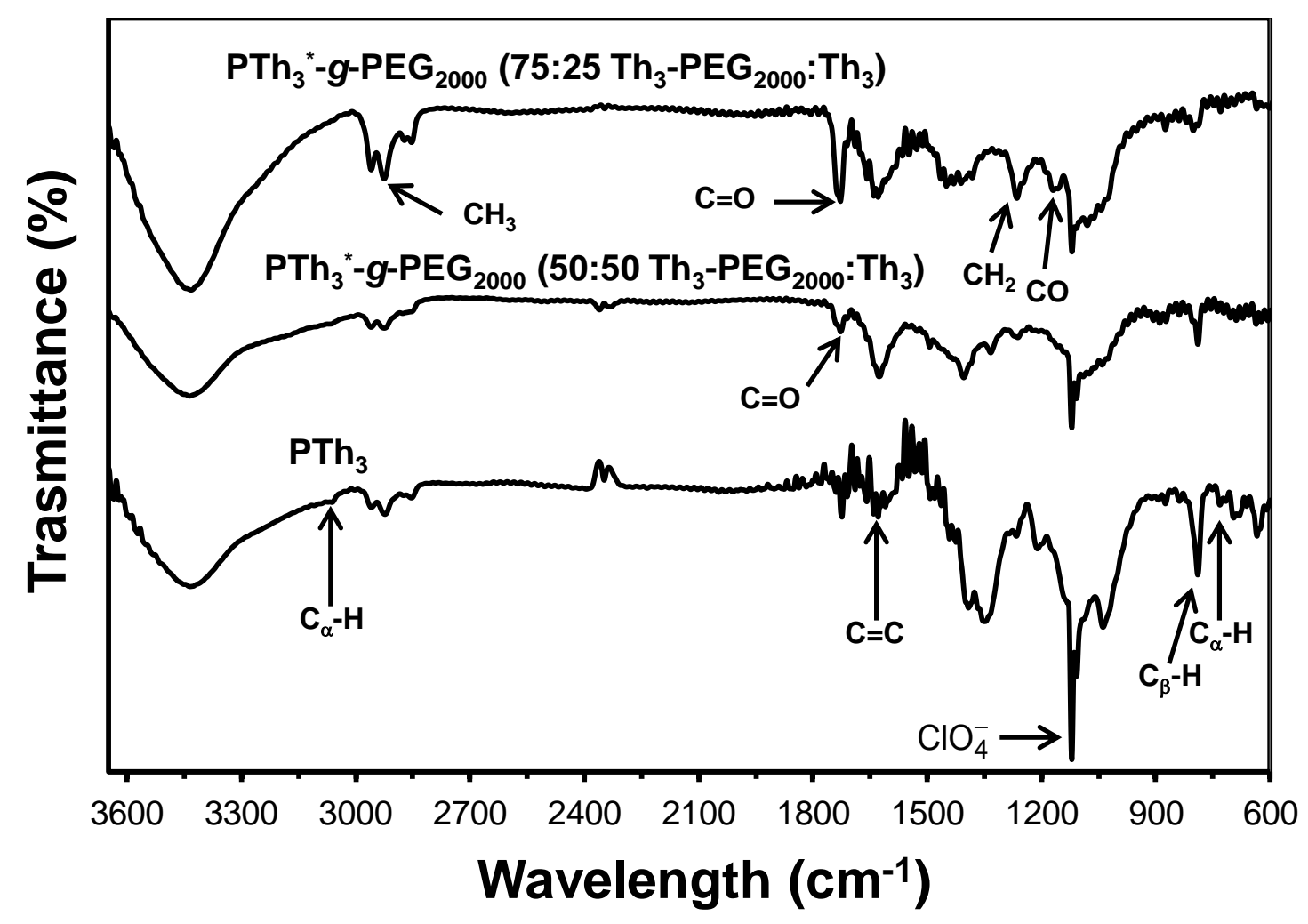

Figure 1 
$\mathrm{PTh}_{3}{ }^{*}-g-\mathrm{PEG}_{2000}\left(75: 25 \mathrm{Th}_{3}-\mathrm{PEG}_{2000}: \mathrm{Th}_{3}\right)$

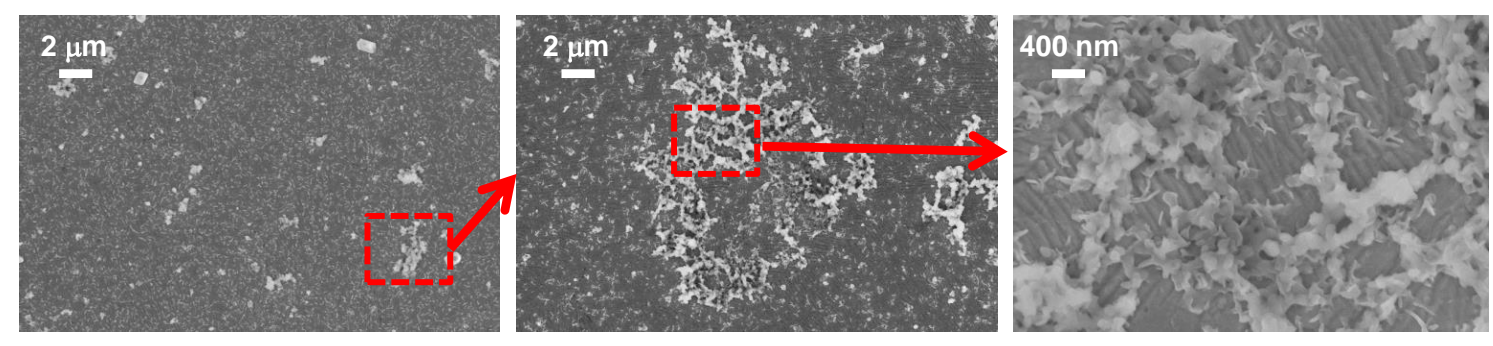

$\mathrm{PTh}_{3}{ }^{*}-g-\mathrm{PEG}_{2000}\left(50: 50 \mathrm{Th}_{3}-\mathrm{PEG}_{2000}: \mathrm{Th}_{3}\right)$

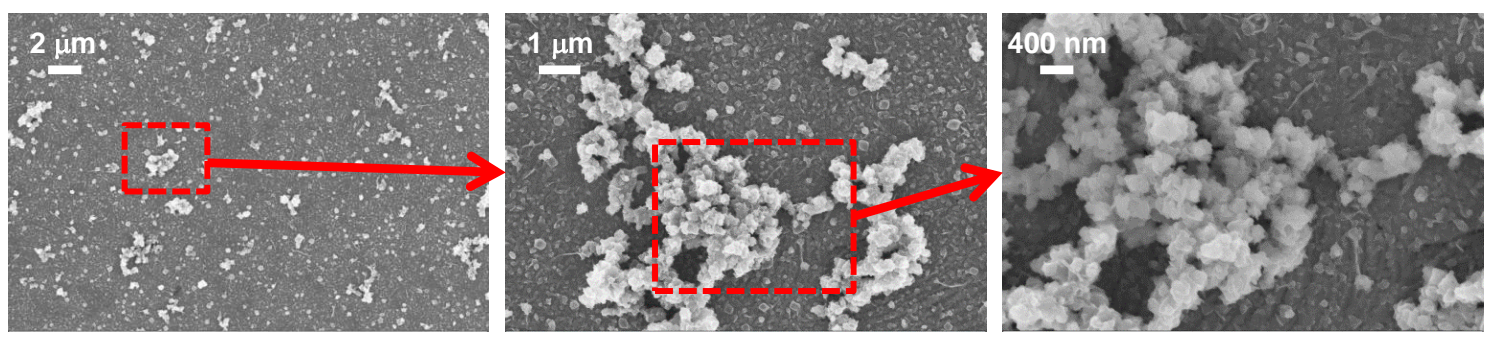

PTh $_{3}$

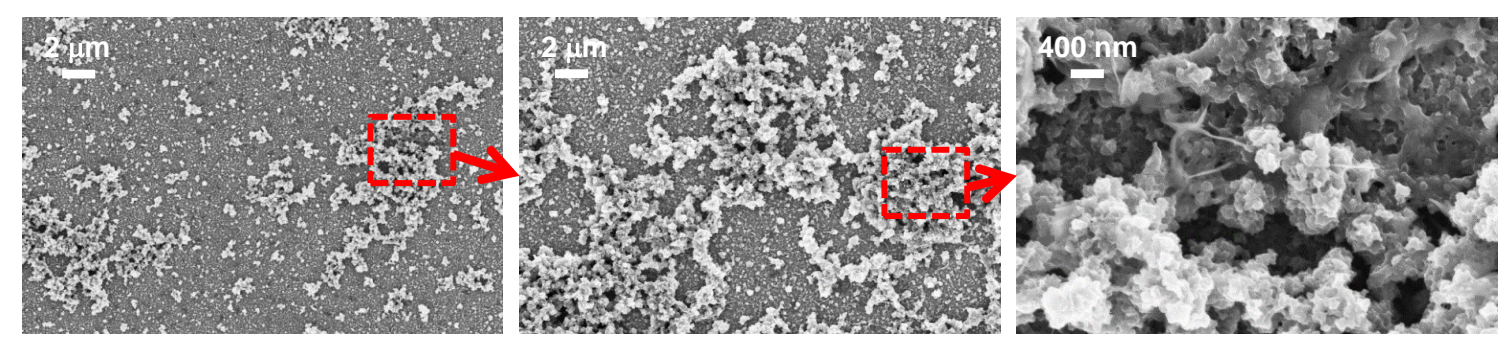

Figure 2 


\section{$\mathrm{PTh}_{3}{ }^{*}-g-\mathrm{PEG}_{2000}\left(75: 25 \mathrm{Th}_{3}-\mathrm{PEG}_{2000}: \mathrm{Th}_{3}\right)$}
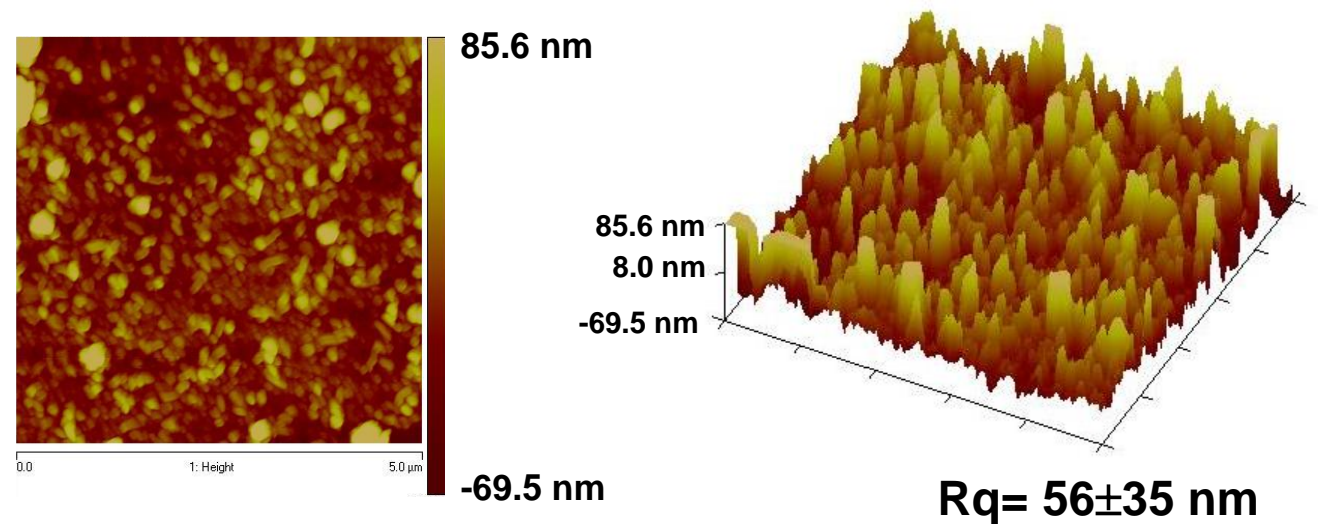

\section{$\mathrm{PTh}_{3}{ }^{*}-g-\mathrm{PEG}_{2000}\left(50: 50 \mathrm{Th}_{3}-\mathrm{PEG}_{2000}: \mathrm{Th}_{3}\right)$}

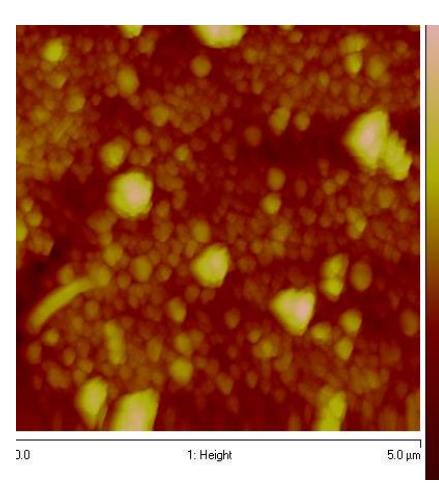

$297.7 \mathrm{~nm}$

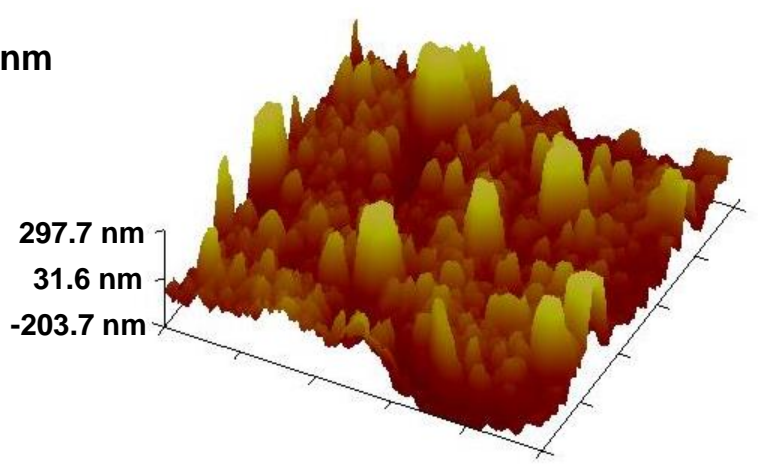

$-203.7 \mathrm{~nm}$

$$
\mathrm{Rq}=\mathbf{7 4} \pm 15 \mathrm{~nm}
$$

\section{$\mathrm{PTh}_{3}$}

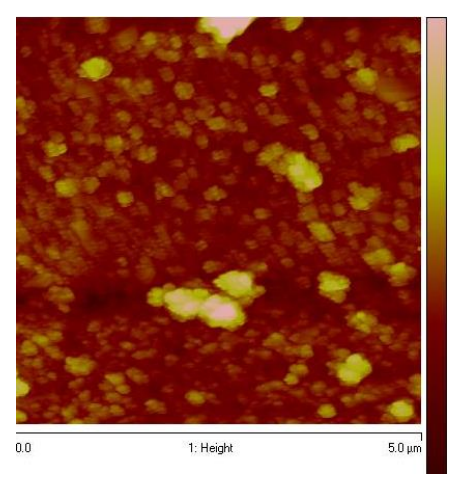

$455.7 \mathrm{~nm}$

$-270.8 \mathrm{~nm}$

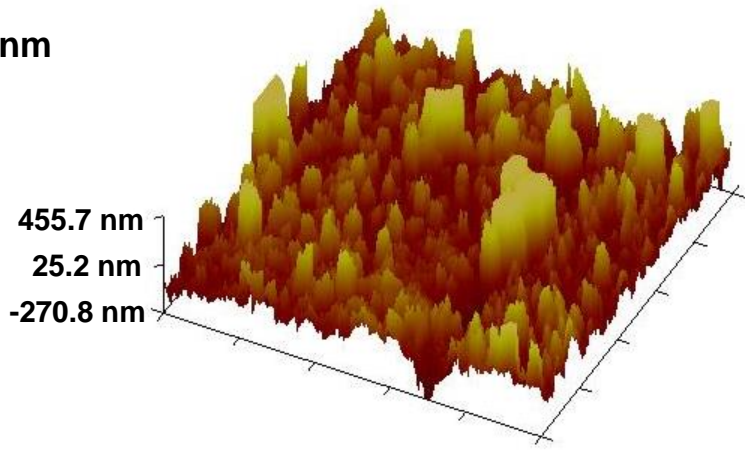

$R q=137 \pm 52 \mathrm{~nm}$

Figure 3 

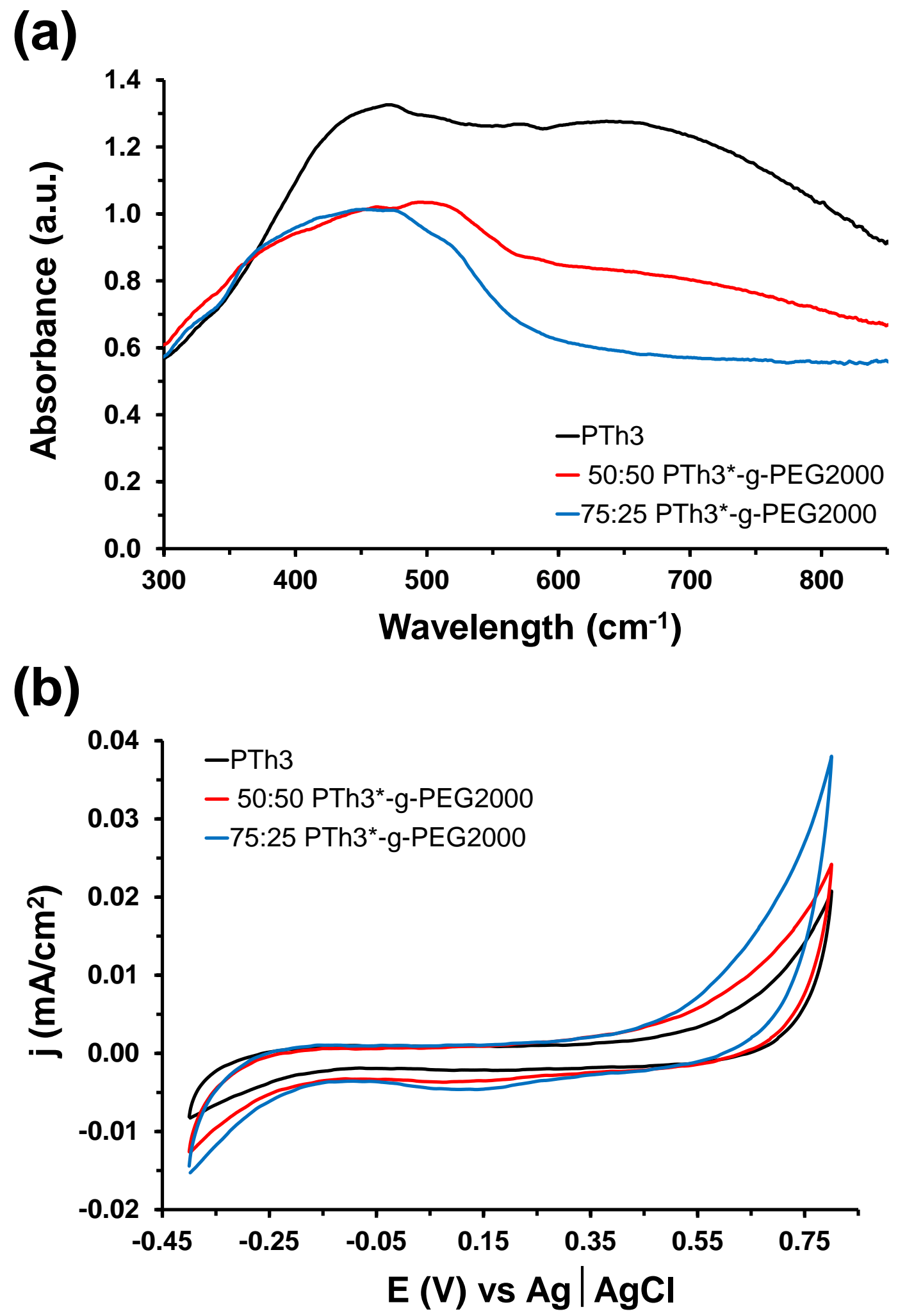

Figure 4 


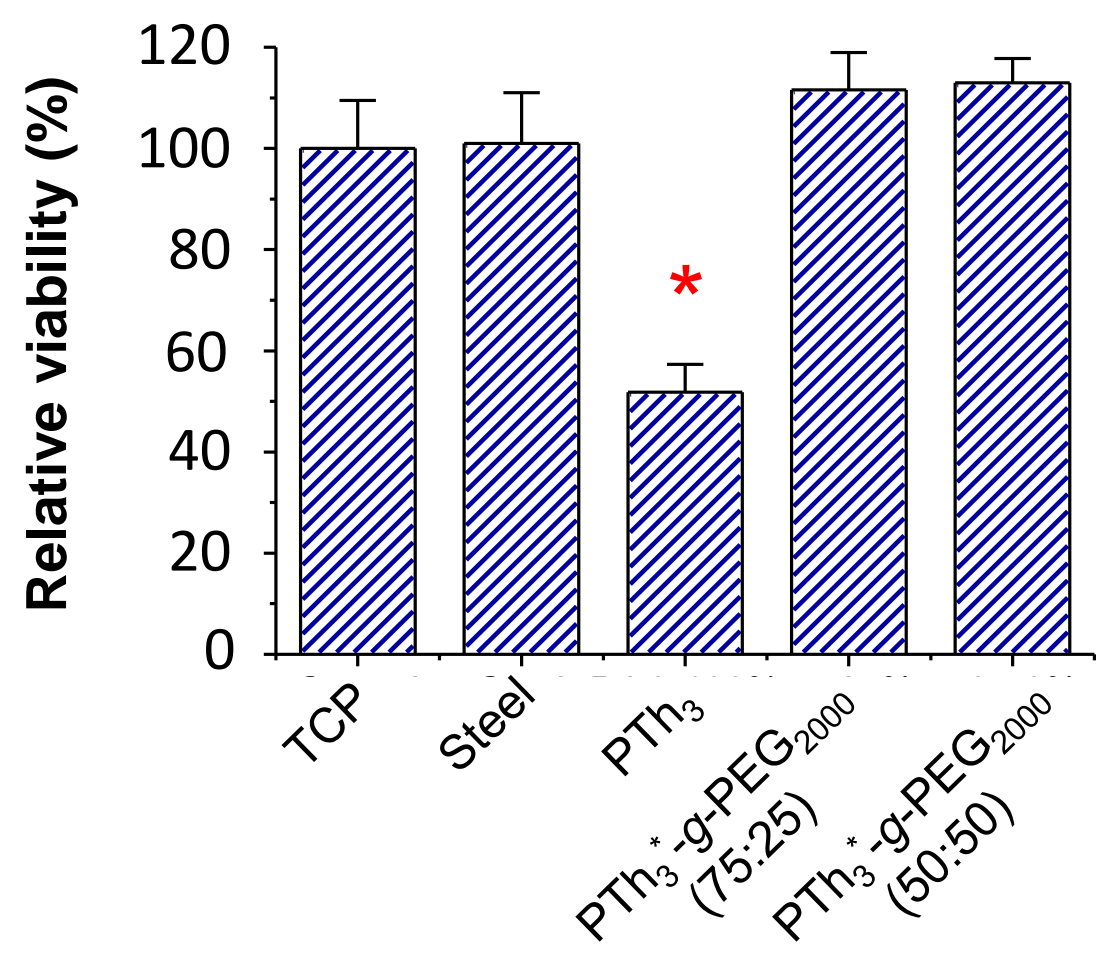

Figure 5 


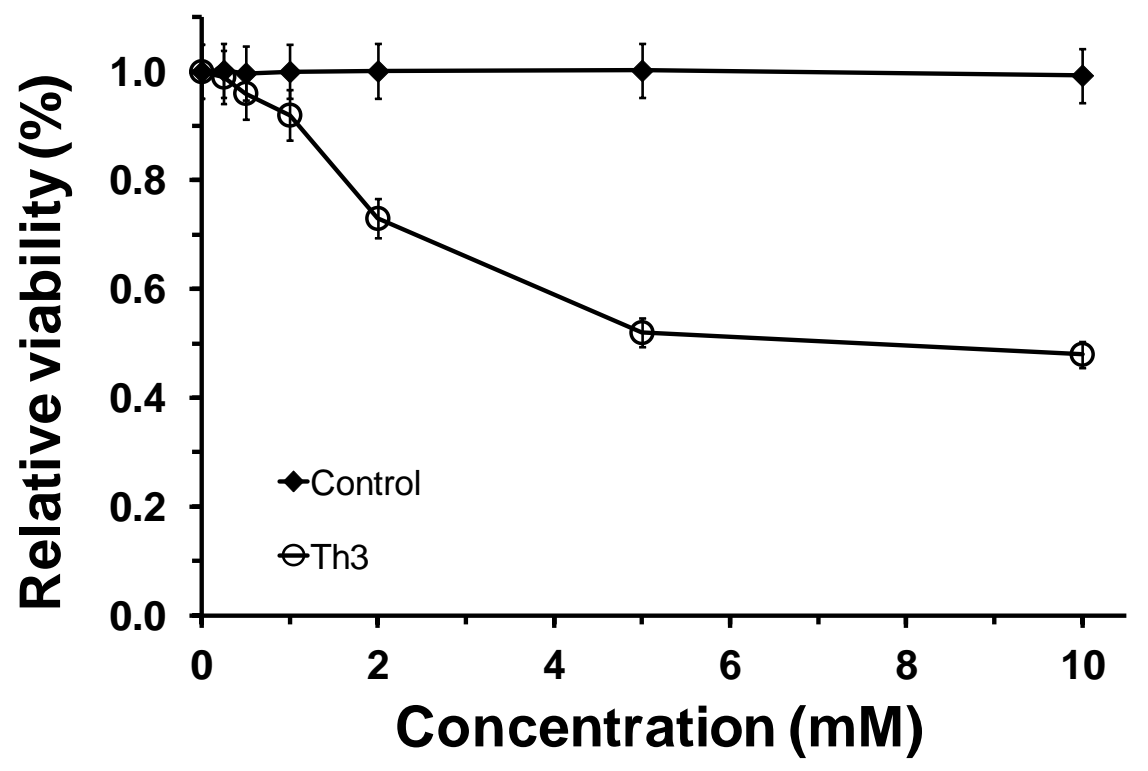

Figure 6 

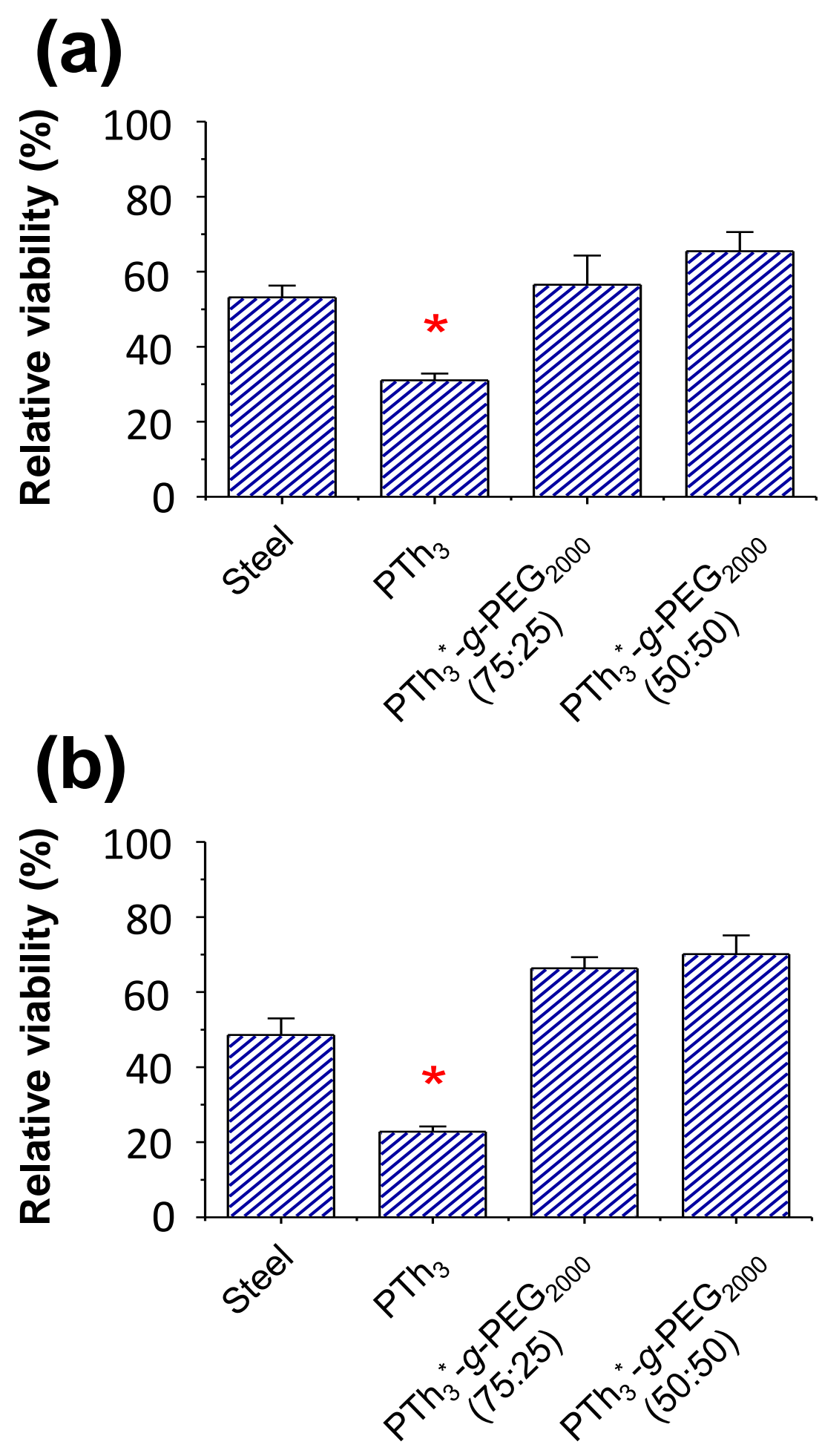

Figure 7 


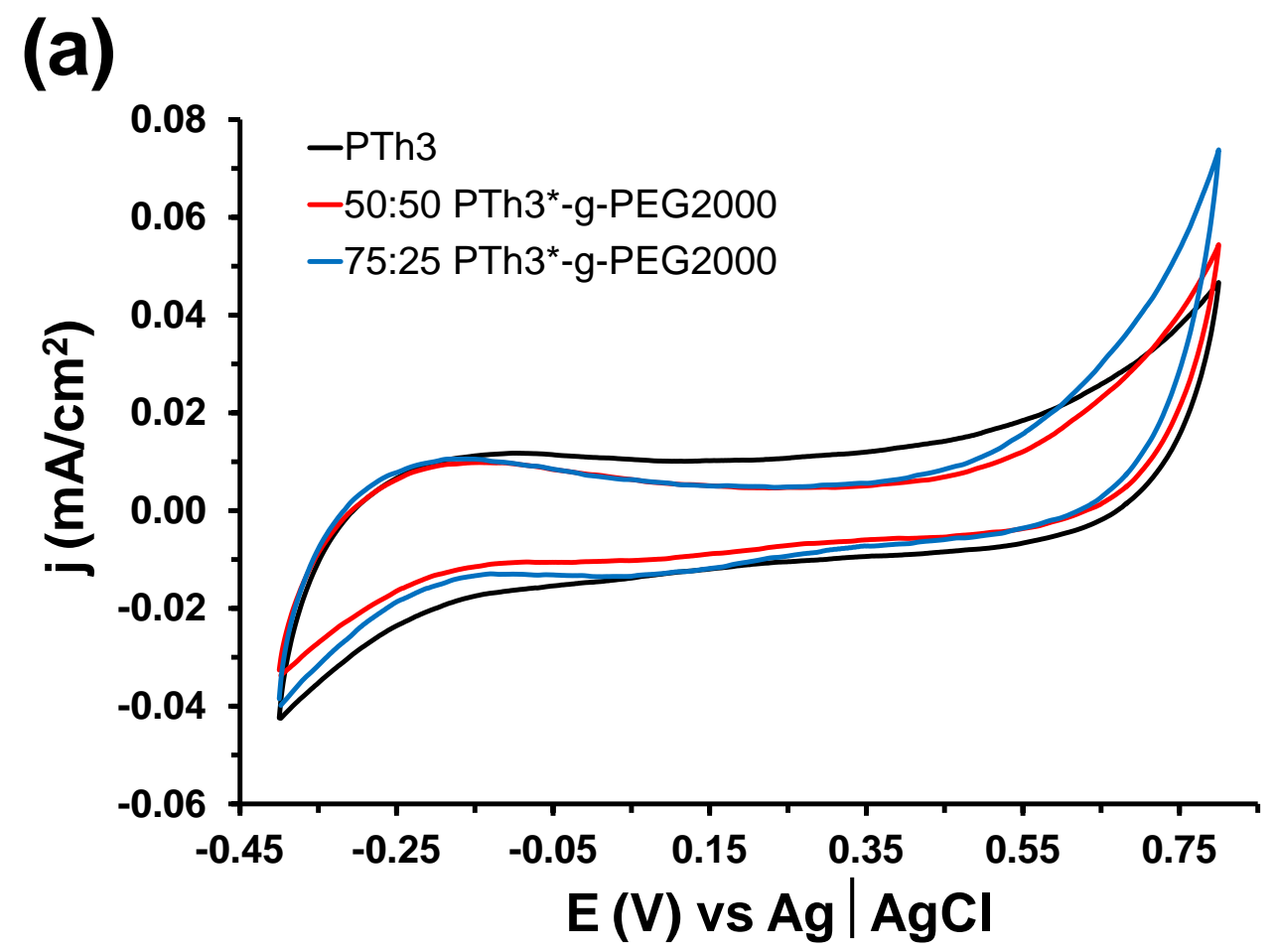

(b)

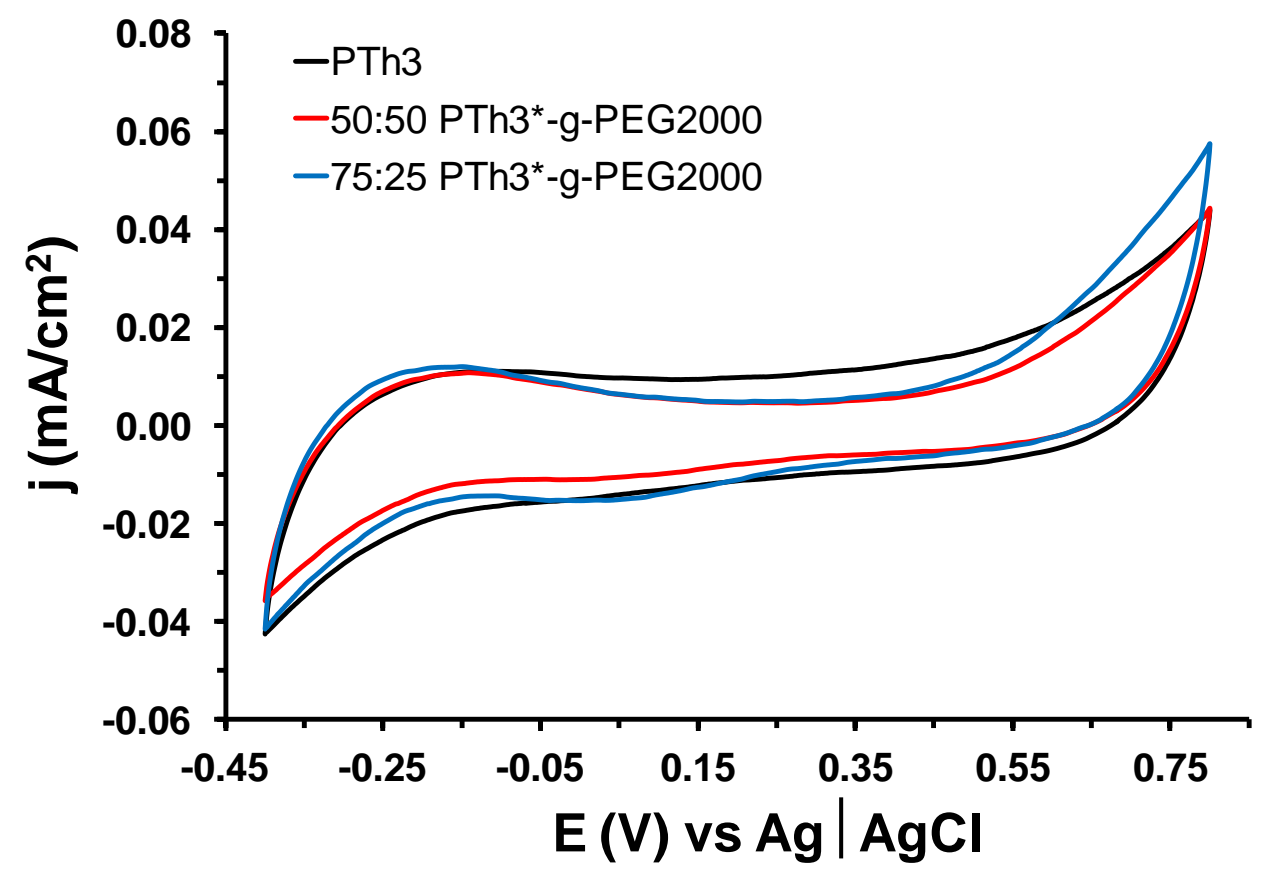

Figure 8 


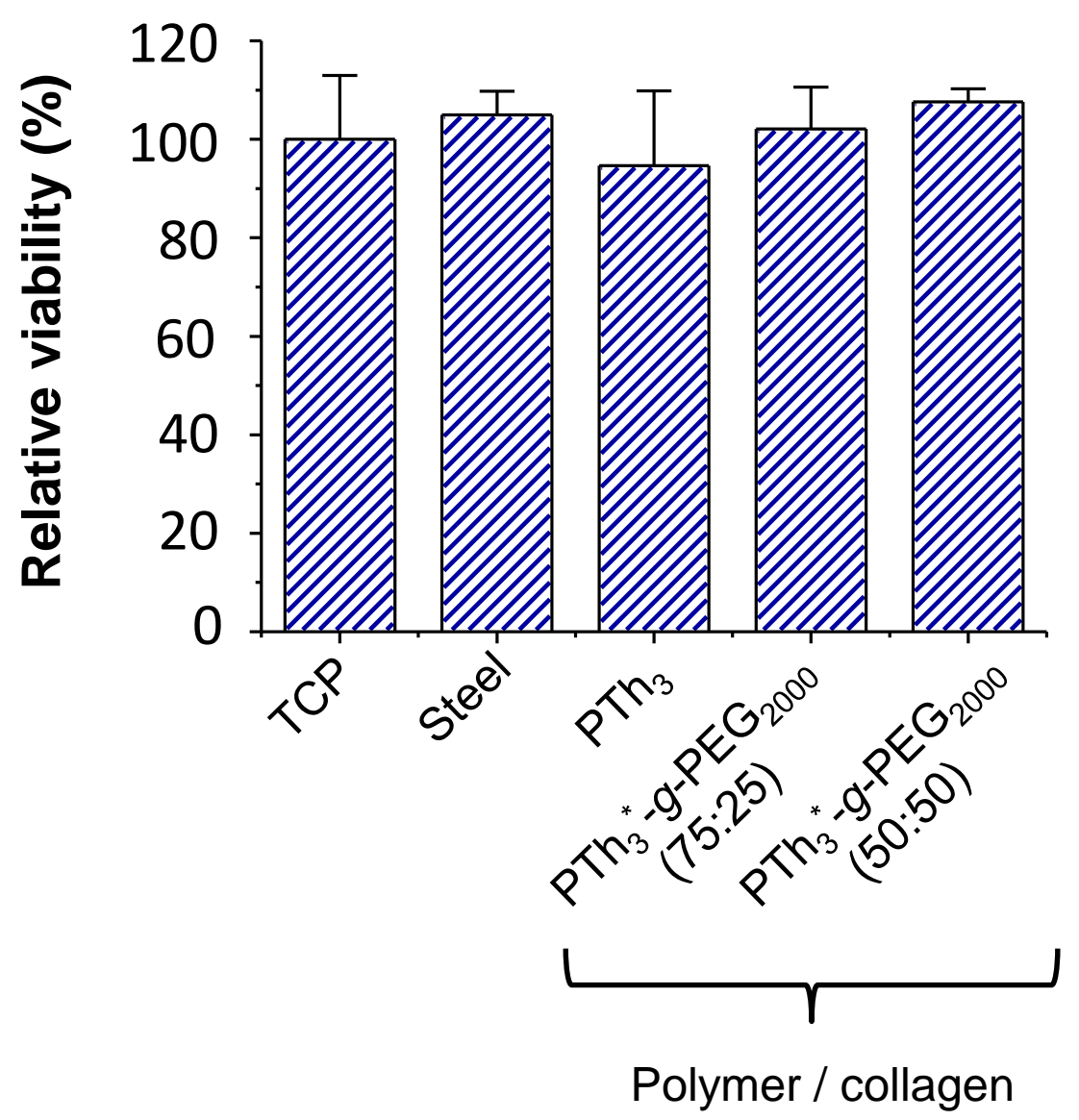

Figure 9 


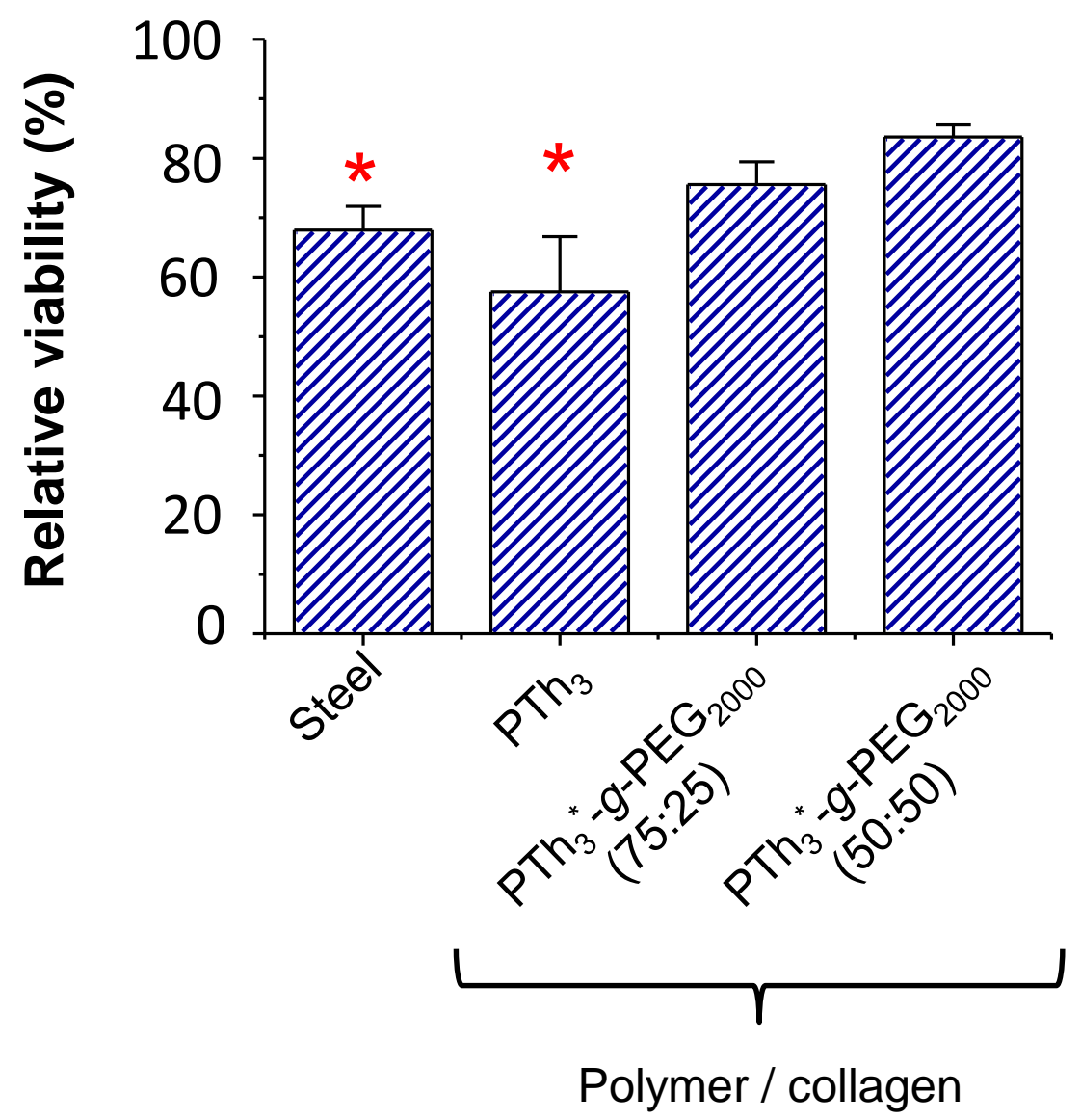

Figure 10 


\section{GRAPHICAL ABSTRACT}

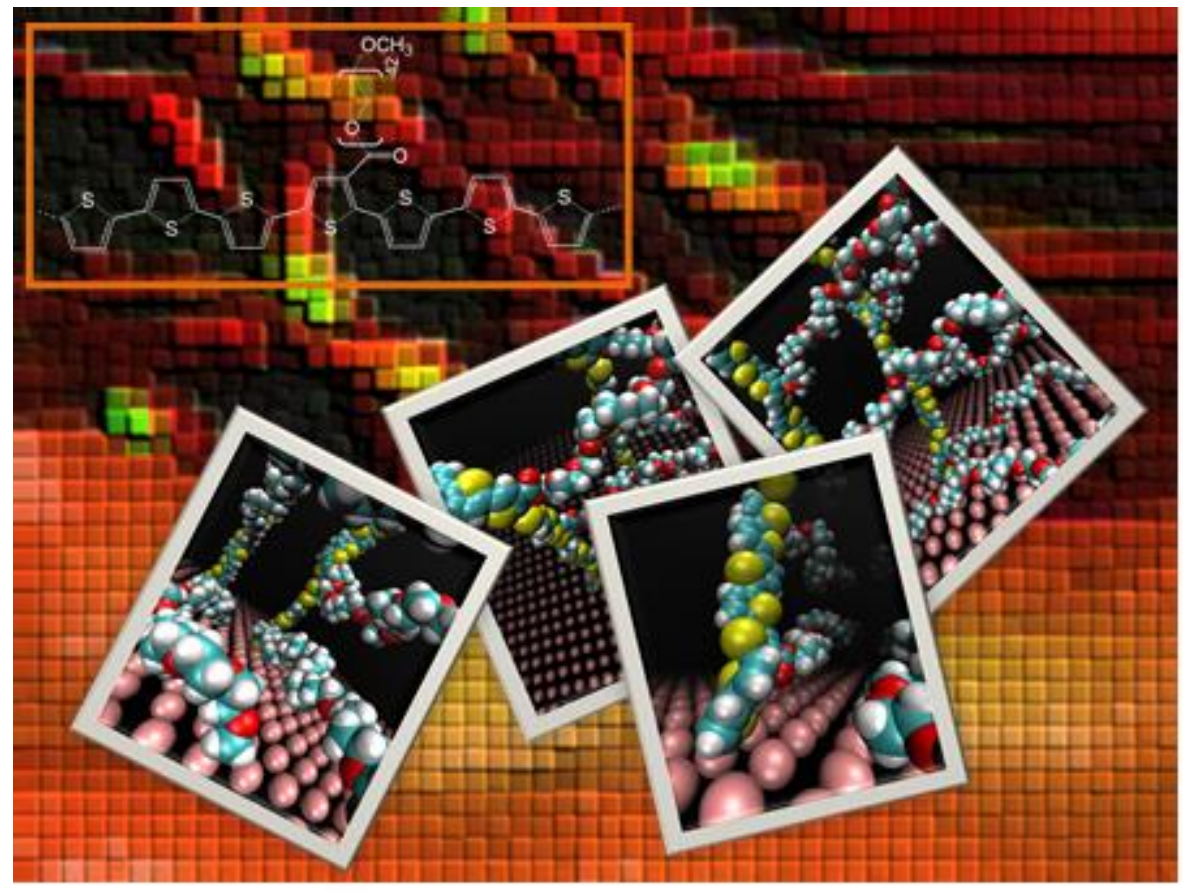

The effects of the poly(ethylene glycol)/thiophene ratio in the physical properties and efficacy as bioactive platforms of polythiophene-g-poly(ethylene glycol) graft copolymers have been investigated. Results indicate that the optical and electrochemical properties, the biocompatibility and the electro-compatibility of polymeric substrates covered by cells of these graft copolymers improves with decreasing poly(ethylene glycol)/thiophene ratio. 